Maria Ångela Dayrell Coelho, **

Suzana Ezequiel da Cunha ${ }^{* * *} \mathbf{e}$

Théa Goifman ****

\title{
Aspectos psicológicos de uma seleção de supervisores de nível médio: pesquisa na área industrial
}

Êste estudo situa-se dentro de uma preocupação corrente $\mathrm{e}$ atual das emprêsas modernas interessadas em investigações, cada vez mais profundas, dos problemas do comportamento humano no trabalho.

Entre êstes está o da seleção de pessoal. Segundo Suzanne, Pacaud, tendo bem definido o cargo, a seleção consiste:

$1 .^{\circ}$ na determinação de aptidões necessárias para o exercer;

2. ${ }^{\circ}$ na escolha dos indivíduos que possuem estas aptidões a um nível suficiente, de tal modo que o exercício do cargo efetue-se satisfatòriamente.

A seleção conduz-se, pois, dentro de um método próprio e a vantagem dêste, na prática, é que sendo bem delimitado o problema, o exame técnico psicológico das aptidóes torna-se menos longo e oneroso.

No caso de supervisão, a seleção não é tão simples pela própria complexidade dos cargos, pois além de comportarem tarefas específicas, adquirem uma feição tôda particular por se tratar de cargos de supervisão; o êxito do supervisor não depende só da eficácia de seus subordinados no trabalho, mas sobretudo do moral industrial, da satisfação ou insatisfação dos operários e de sua atitude frente à emprêsa e à produção.

Podemos perceber, assim, a necessidade de uma seleção científica para que se torne possível a escolha, cada vez mais acertada, daqueles que irão ocupar tais postos.

\subsection{Objetivos da pesquisa}

A pesquisa propôs-se a uma investigação sistemática de tal problema, sendo seus objetivos principais os que relacionamos a seguir:

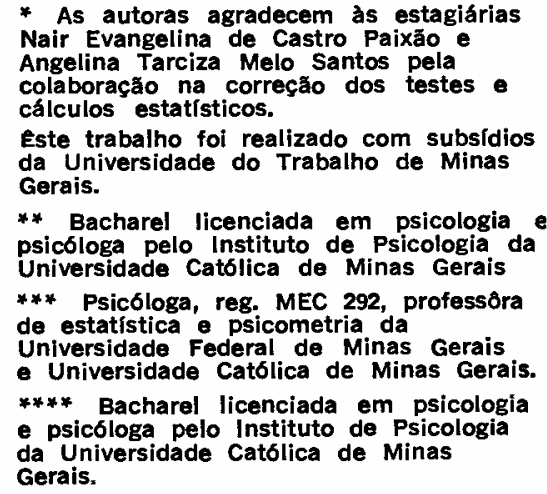
Nair Evangelina de Castro Paixão e Angelina Tarciza Melo Santos pela colaboração na correção dos testes e cálculos estatísticos.

Este trabalho foi realizado com subsidios da Universidade do Trabalho de Minas Gerais.

* Bacharel licenciada em psicologia psicóloga pelo Instituto de Psicologia da Universidade Católica de Minas Gerais

*** Psicóloga, reg. MEC 292, professôra de estatística o psicometria da Universidade Federal de Minas Gerais - Universidade Católica de Minas Gerais. **** Bacharel licenciada em psicologia e psicóloga pelo Instituto de Psicologia da Universidade Católica de Minas Gerais. 
1. Estudo dos traços indispensáveis ao exercício dos cargos de supervisão, tendo em vista a seleção e promoção de pessoal.

\subsection{Estabelecer uma série de} técnicas que tenham um valor de prognóstico para o êxito nos cargos de supervisão.

\section{Levantar escalas de} avaliação para os instrumentos de medida de aptidão, destinados ao serviço de seleção da emprêsa.

\section{Melhor conhecimento do} potencial dos supervisores de nível médio, lotados na companhia na presente data.

5. Apresentar sugestões para a formação e desenvolvimento do pessoal, no sentido de que cada um produza o máximo dentro de suas potencialidades.

\subsection{A população estudada}

Dado à importância e à necessidade de se realizar um estudo mais detalhado e profundo na área de supervisão média da emprêsa, resolvemos trabalhar com tôda a população, num total de 383 supervisores.

Entre os 383 convocados, tivemos um grupo de 318 que participou totalmente dos trabalhos, o que representa $83 \%$ da população.

Na emprêsa, os cargos de supervisão média são assim denominados: chefe-contramestre, contramestre, auxiliar administrativo, auxiliar técnico, chefe de grupo e chefe de equipe.

Antes de descrevermos a população quantitativamente, daremos uma definição sucinta de cada cargo quanto à subordinação ao nivel de supervisão exercida e características importantes ao cargo.
Chefe-contramestre. É um cargo de supervisão intermediária. Coordena dentro de um setor um grupo de trabalho; subordinado ao chefe de setor, pôsto ocupado, na emprêsa, principalmente por engenheiros. Supervisiona contramestres nas respectivas áreas.

Contramestre. Subordinado ao chefe-contramestre ou em alguns casos ao próprio chefe de setor. Supervisiona diretamente os operários ou chefes de turma.

\section{Auxiliar administrativo.}

Responsável pela supervisão, coordenação e execução dos trabalhos burocráticos no escritório do setor. Subordinado aos chefes de departamento, serviço ou setor, funções exercidas por engenheiros.

Auxiliar técnico. Auxilia a chefia e supervisores do setor na solução de problemas técnicos, exercendo por vêzes a supervisão. Subordinado ao chefe de setor.

Chefe de grupo. E um cargo correspondente ao nivel de chefe-contramestre. Subordinado ao chefe de departamento ou seção; supervisiona auxiliares administrativos ou

funcionários que se dedicam a atividades técnicas, burocráticas ou administrativas.

Chefe de equipe. Subordinado ao Chefe de assessoria. Supervisiona funcionários em atividades técnicas, burocráticas ou administrativas. Este cargo é específico dos órgãos de assessoria à gerência da usina.

Para a coleta de dados pessoais dos supervisores recorremos, especialmente, a duas fontes a saber:

a) questionários de descrição de cargos;

b) ficha-registro de empregados da emprêsa.
Os supervisores estariam assim distribuídos:

\section{1. ${ }^{\circ}$ Segundo a escolaridade.}

39 supervisores possuem o primário incompleto, o que equivale a $12 \%$ da população; 134 têm o primário completo, $42 \%$ da população; ginasial, 29 indivíduos, ou seja, $9 \%$ da população e os 116 restantes são técnicos de nível médio correspondendo a $37 \%$ da população.

Para efeito de estudo, dividimos os supervisores em apenas dois grupos: técnicos e não técnicos. Serão chamados na pesquisa sob o título de "técnicos" aquêles que possuem o curso técnico de nível médio, e de "não técnicos" os que possuem o curso primário incompleto, primário completo e ginasial.

\section{Distribuição segundo os} cargos.

São 29 chefes-contramestres (CCM), correspondendo a $9 \%$ da população: 15 técnicos e 14 não técnicos; 182 contramestres (CM), $5 \%$ da população: 52 técnicos e 130 não técnicos; 36 auxiliares técnicos (AT), $11 \%$ da população: 30 técnicos e 6 não técnicos; 44 auxiliares administrativos $(A A), 14 \%$ da população: 11 técnicos e 33 não técnicos; 9 chefes de grupo, $3 \%$ da população: 3 técnicos e 6 não técnicos; 18 chefes de equipe, $6 \%$ da população: 5 técnicos e 13 não técnicos.

Para efeito de estudo dos cargos, os chefes de grupo e chefes de equipe foram agrupados e serão apontados na pesquisa sob o título de "demais supervisores" (DS).

\section{Distribuição segundo o} sexo.

A população descrita pela pesquisa é tôda ela do sexo masculino.

4. Distribuição segundo a idade. 
TABELA 1

Distribuição segundo a idado

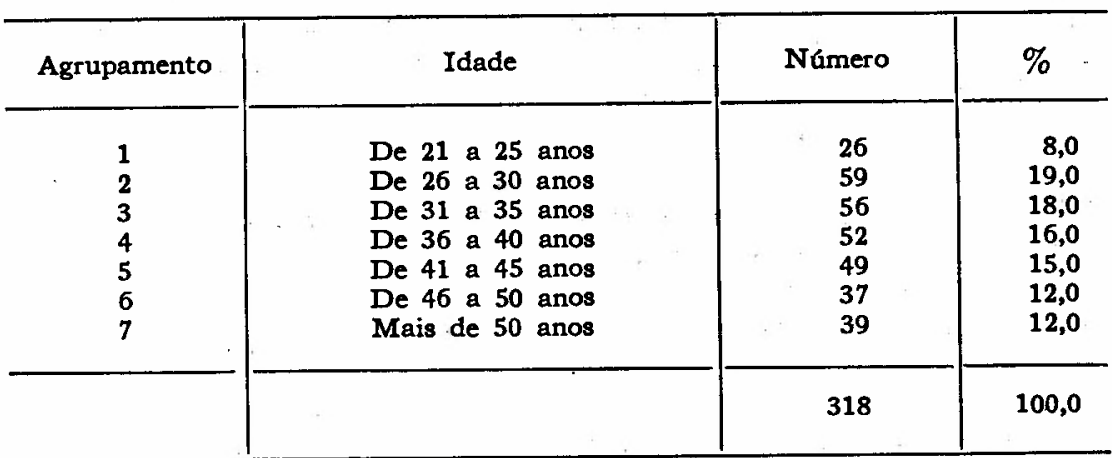

5. ${ }^{\circ}$ Distribuição segundo 0 tempo de companhia.

TABELA 2

Distribuição segundo o tempo de companhia

\begin{tabular}{c|c|c|c}
\hline \multirow{2}{*}{ Agrupamento } & Tempo de companhia & Numero & $\%$ \\
\cline { 2 - 4 } 1 & Menos de 1 ano & 15 & 5,0 \\
2 & De 1 a 2 anos & 16 & 5,0 \\
3 & De a 3 anos & 12 & 4,0 \\
4 & De a 5 anos & 15 & 5,0 \\
5 & De a 10 anos & 100 & 14,0 \\
6 & De 10 a 20 anos & 115 & 31,0 \\
7 & Mais de 20 anos & 318 & 100,0 \\
\hline
\end{tabular}

6. Distribuição segundo 0 tempo de supervisão.

TABELA 3

Distribuição segundo o tempo de supervisão

\begin{tabular}{c|c|c|c}
\hline Agrupamento & Tempo de supervisão & Número & $\%$ \\
\cline { 2 - 4 } 1 & Menos de 1 ano & 36 & 10,0 \\
2 & De 1 a 2 anos & 75 & 24,0 \\
3 & De a 5 anos & 46 & 15,0 \\
4 & De a 10 anos & 72 & 22,0 \\
5 & De 11 a 20 anos & 67 & 22,0 \\
6 & Mais de 20 anos & 3,0 \\
\hline & & 318 & 100,0 \\
\hline
\end{tabular}

7.0 Para estudar algumas hipóteses levantadas achamos necessário agrupar a população segundo três características específicas inter-relacionadas, a saber: idade, tempo de companhia e tempo de supervisão.

Como não nos seria possível o estudo de todos os agrupamentos obtidos, escolhemos oito dêles por serem mais densos:

1. Segundo idade $(+$ de 50 anos) e tempo de companhia ( + de 20 anos): 33 supervisores.

2. Segundo idade $(+$ de 50 anos) e tempo de supervisão (t de 20 anos): 15 supervisores.

3. Segundo idade (de 21 a 25 anos) e tempo de companhia (menos de 1 ano): 7 supervisores.
4. Segundo idade (de 21 a 25 anos) e tempo de supervisão (menos de 1 ano): 12 supervisores.

5. Segundo idade (de 26 a 30 anos) e tempo de companhia (de 5 a 10 anos): 18 supervisores.

6. Segundo idade (de 31 a 35 anos) e tempo de supervisão (de 6 a 10 anos): 20 supervisores.

7. Segundo idade (de 41 a 45 anos) e tempo de companhia (mais de 20 anos): 37 supervisores.

8. Segundo idade (de 26 a 30 anos) e tempo de supervisão (de 1 a 2 anos): 28 supervisores.

\subsection{Hipóteses}

Ao iniciarmos, procuramos alinhar algumas hipóteses, as quais norteariam nossas pesquisas. Estas seriam básicas ao alcance dos objetivos propostos. A partir destas hipóteses seriam utilizados vários instrumentos: uma bateria fatorial, cujos resultados chamaremos de rendimento; duas fichas de avaliação de desempenho na função e uma entrevista pela qual atribuiremos graus.

A primeira abordagem teria em vista relacionar o grupo de supervisores técnicos com 0 de supervisores não técnicos nos três aspectos medidos.

Na segunda, estudaríamos os supervisores pelos respectivos cargos e, em decorrência disso, tiraríamos algumas conclusões, baseadas em relações subjacentes, sem qualquer previsão anterior.

Em terceiro lugar, procuraríamos estabelecer relações entre os resultados obtidos com algumas variáveis relevantes, tais como: idade de supervisor, 
seu tempo de companhia e de prática na supervisão, variáveis estas de interêsse para o nosso trabalho. Estarlamos

interessados, principalmente, em ter alguma informação sôbre a influência destas variáveis como fatôres de desempenho profissional.

Assim sendo, levantamos as seguintes hipóteses:

\section{1. ${ }^{a}$ Sabemos que os examinandos com formação técnica fizeram o curso técnico de nível médio completo enquanto a formação do outro grupo varia da semi-alfabetização até o curso colegial incompleto. Assim, as médias dos rendimentos dos supervisores com formação técnica seriam significativamente superiores às dos supervisores não técnicos.}

2. ${ }^{a}$ Com relação à avaliação do supervisor no seu desempenho profissional, utilizariamos as duas fichas mencionadas. Julgamos que as médias das avaliações dêstes dois instrumentos iriam diferir; portanto, a média das duas avaliações seria a melhor estimativa do desempenho na função do que cada uma tomada separadamente. Levantamos, então, a hipótese de que o grupo técnico teria média de avaliação significativamente superior à média dos não técnicos.

3. Q Quanto aos resultados das entrevistas, esperamos melhores graus entre os supervisores de formação técnica. Julgamos que esta formação proporcionaria ao supervisor maior segurança e confiança em si, paralelamente à expectativa de melhores salários e, conseqüentemente, ajustamento profissional positivo.

\section{4. ${ }^{\text {a }}$ Os supervisores com}

formação técnica apresentariam seus resultados, tanto na bateria fatorial como no desempenho funcional, mais saturados de fatôres específicos do que os supervisores não técnicos.

Entre êstes, um fator geral seria - maior responsável pelo rendimento dos examinandos, nos dois aspectos.

5. Numa segunda abordagem, como ficou dito, levantamos hipóteses tendo em vista o estudo dos examinandos agrupados pelos seus respectivos cargos. Em todos os cargos encontramos supervisores com formação acadêmica, distribuídos aleatòriamente. Sendo assim, não esperamos superioridade de resultados em qualquer dos cargos e em qualquer dos três aspectos considerados: rendimento nos testes fatoriais, notas de avaliação do desempenho na função e graus alcançados na entrevista.

Depois de levantadas as hipóteses, voltamos nossas atenções para aquelas variáveis que poderiam interferir no comportamento dos resultados dos supervisores, principalmente, em relação ao seu desempenho na função.

Muitas questões poderiam ser levantadas e solucionadas pelo menos em parte; mas, como o contrôle de tôdas as variáveis intervenientes ser-nos-ia impossível, estudaríamos apenas as relações entre a idade do supervisor, o seu tempo de supervisão e seu tempo de trabalho na companhia.

Sendo calculadas as estatísticas dos agrupamentos mais densos, algumas inquirições surgiriam:

1. Comparando o grupo mais jovem com o mais idoso, encontrariamos alguma diferença considerável na avaliaçã̃o do desempenho na função? Seria a idade fator de sucesso profissional?

2. O tempo de supervisão estaria associado a melhor desempenho funcional? Ou, por outra, o grupo com maior experiência de supervisão apresentaria melhores resultados de desempenho, independente da idade do supervisor?

3. O tempo de companhia seria fator de sucesso na função?

\section{METODOLOGIA}

Voltando aos objetivos a serem alcançados por êste trabalho e, considerando os dados experimentais que poderiam ser colhidos por nós, empenhamo-nos, principalmente, em estabelecer meios que nos possibilitassem extrair o máximo de informações a partir dêsses dados. As hipóteses estavam formuladas, é certo, mas eleger instrumentos de medida eficazes das variáveis em função e as técnicas estatísticas mais adequadas para testar as hipóteses levantadas constituiu para nós grande preocupação.

Com grande critério planejamos e examinamos os possiveis instrumentos a serem empregados e sua adequação aos dados e aos modelos teóricos existentes. A partir de várias considerações prévias estabelecemos, com rigor, nosso método de trabalho.

\subsection{A eleição dos testes}

Como já vimos, para uma seleção eficiente, é necessário que se definam, tão explicitamente quanto possivel, a natureza e as atribuições típicas das funções para as quais se seleciona pessoal.

Portanto, a determinação do processo seletivo condiciona-se fundamentalmente, às exigências de cada cargo.

No nosso estudo, para a escolha dos testes, tentamos determinar os requisitos gerais de um supervisor, baseando-nos numa descrição do Occupational classification (U.S. Department 
of Labor), os quais relacionamos a seguir:

1. estar familiarizado com um ou mais serviços;

2. ter habilidade para planejar e dirigir atividades de maneira

a promover um esfôrço coordenado e terminar o trabalho em tempo hábil;

3. ter habilidade para se comunicar efetivamente com subordinados e superiores;

4. ter habilidade para redigir relatórios;

5. ter habilidade para estimar quantidades e custos de materiais;

6. ter percepção

administrativa para descobrir erros em documentos;

7. ter habilidade em motivar pessoas a trabalhar com consciência e cooperação em atividades que envolvam contatos;

8. ter habilidade para executar o trabalho dos subordinados;

9. ter habilidade para treinar novos empregados.

Pesquisamos, então, diversos testes e baterias com a finalidade de selecionar aquêles que seriam mais adequados à população em estudo, sendo escolhida a bateria CEPA.

Encontramos algumas vantagens no uso da citada bateria. Os testes que a compõem foram estudados durante muitos anos por vários serviços de psicologia, quando foram feitos cálculos de validade, de precisão e análise de seus itens baseados em grandes populações. A partir dêsses estudos, os testes foram padronizados.

Além disso, cada prova é apresentada independentemente e só é usada uma vez, pois as respostas são escritas no próprio teste. Esste aspecto foi importante na nossa escolha pela facilidade de seu manuseio pelos examinandos, bem como economia de esfôrço e tempo.

As escalas de percentis encontradas no manual da bateria não foram utilizadas por nós, pois as mesmas foram levantadas sôbre amostras de adolescentes estudantes de diversas escolas. Já nossa população industrial, como dissemos, compõe-se de pessoas com níveis de escolaridade que variam de semi-alfabetizados até curso técnico de nível médio e de idades entre 21 e 67 anos, motivos pelos quais procuramos levantar as nossas próprias escalas de avaliação.

Voltando à descrição sumária da supervisão, verificamos que várias aptidões ali relacionadas podem ser avaliadas pelos testes fatoriais, mas outras só poderiam ser aquilatadas por meio de entrevistas.

Excluímos, no nosso trabalho, o fator $M$. $O$ teste exige certa agilidade para escrever, e como grande parte da nossa população não tem essa aptidão, provàvelmente, não atingiria seus objetivos.

Além dos testes fatoriais, pensamos em introduzir na pesquisa um teste de personalidade e a escolha recaiu sôbre o Rorschach, embora soubéssemos que gastaríamos muito tempo em sua aplicação, por ser grande - número de nossos examinandos.

Mas, por tratar-se de um teste que nos daria um conhecimento das

possibilidades de atuação

profissional e uma compreensão global do indivíduo e também pela sua riqueza e profundidade estrutural, diagnóstica e prognóstica - optamos, sem vacilar, por sua inserção.
Deveríamos, no entanto, proceder com prudência, pois êste campo é totalmente inédito na emprêsa e o é, em geral, na indústria.

De acôrdo com o nosso planejamento, êle seria aplicado após a bateria fatorial. Mas, já nesta ocasião, observamos grande resistência aos testes, sendo manifestada uma atitude receosa $e$ desconfiada por parte de muitos.

Pudemos levantar a hipótese de que seria muito difícil conseguir, na aplicação do Rorschach, uma atitude favorável dos indivíduos, o que repercutiria prejudicialmente sôbre o resto do trabalho, no caso sôbre as entrevistas, podendo até ocasionar 0 não-comparecimento de muitos às mesmas, o que nos seria prejudicial.

Resolvemos, então, não correr 0 risco principalmente por têrmos conhecimento que, em pesquisas realizadas no meio industrial, tal resistência ao teste de personalidade já foi comprovada, tendo, por isto, sido eliminado do contexto das mesmas.

\subsection{Preparo psicológico do pessoal - Reunião A}

Uma vez escolhidos os testes que seriam utilizados na pesquisa, seguiu-se sua aplicação, tendo havido antes uma reunião, em pequenos grupos, com todos os supervisores, com o objetivo primeiro de prepará-los para a realização dos testes $\mathrm{e}$ entrevistas, apresentar-Ihes o plano global do estudo, explicar-lhes suas finalidades e, por fim, solicitar sua colaboração.

Fêz-se a convocação do pessoal por meio de uma carta, sendo as datas e horários estabelecidos antes, com a cooperação dos chefes de setores e departamentos da usina, de acôrdo com as disponibilidades 
dos mesmos no horário de trabalho, obedecendo a seguinte ordem:

\section{1. ${ }^{\circ}$ Chefes-contramestres \\ 2. Contramestres.}

3. Auxiliares administrativos.

4..$^{-}$Auxiliares técnicos.

5. Chefes de grupo, chefes de equipe e outros.

Iniciamos o trabalho com os chefes-contramestres pelos motivos que apresentamos a seguir:

a) E de praxe, na emprêsa, fazerem-se as comunicações, sempre de cima para baixo, respeitando, dêste modo, a linha hierárquica da emprêsa.

Evita-se, com isto, determinados sentimentos que possam ocorrer, quais sejam: desejo de não colaborar ou impedir as as realizações.

b) Pedir sua colaboração, pois seu assentimento pessoal teria uma repercussão positiva na usina, favorecendo o comparecimento dos outros supervisores às reuniões seguintes.

Na seqüência dos demais grupos não houve critérios dignos de menção.

Então, tivemos:

a) 2 (dois) grupos de chefes-contramestres;

b) 16 (dezesseis) grupos de contramestres;

c) 3 (três) grupos de auxiliares administrativos;

d) 3 (três) grupos de auxiliares técnicos;

e) 2 (dois) grupos de chefes de grupo;

f) 2 (dois) grupos de chefes de equipe e outros.

Como na emprêsa as notícias correm com grande rapidez entre o pessoal, pela facilidade de contato existenie, tentou-se realizar as reuniões num espaço de tempo o mais breve possivel, para que todos recebessem as mesmas informações e tivessem suas dúvidas esclarecidas, evitando-se que os objetivos da pesquisa fôssem mal interpretados.

Dos 383 supervisores convocados, houve um comparecimento de 333 a essa reunião, o que significa $87 \%$ da população. Dos 50 ausentes, os motivos alegados, entre outros, foram relativos a férias, doenças e afastamentos diversos.

As reuniões tiveram como preocupação primeira motivar os supervísores para a pesquisa, considerando-os sempre como colaboradores na resolução de um problema comum e interessando-os pelo bom êxito do trabalho.

Após a acolhida dos participantes, assentamo-nos em círculo para favorecer o diálogo, havendo a distribuição de crachás para identificação, o que veio facilitar o tratamento nominal dos supervisores, pelo monitor.

Iniciamos pela apresentação do esquema de trabalho, para conhecimento do plano global da pesquisa, havendo em seguida os debates.

Entre outros aspectos, deixamos bem claro os nossos objetivos, os quais poderíamos resumir como se segue:

a) melhor aproveitamento dos empregados na usina, tendo em vista a promoção;

b) seleção de novos empregados (admissão);

c) conhecimento das exigências dos cargos de supervisão, visando a formação e o desenvolvimento dos atuais supervisores da usina.
A partir da questão apresentada sôbre aptidões e habilidades indispensáveis ao exercício dos cargos de supervisão, seguiu-se uma série de debates fazendo um paralelo com uma pesquisa norte-americana, ${ }^{1}$ onde foi feito um levantamento de traços de maior e menor importância para a supervisão.

Aproveitamos então o momento, para se fazer, em grupo, a avaliação por pontos dêstes traços, os quais relacionamos a seguir:

1. Instrução. 2. Inteligência. 3. Conhecimentos gerais. 4. Conhecimento do trabalho supervisionado. 5. Habilidade no trabalho supervisionado. 6 .

Visão. 7. Audição. 8. Aptidão para falar. 9. Conhecimento de relações humanas. 10. Rapidez para tomar decisões. 11.

Precisão. 12. Experiência. 13. Memória de nomes. 14.

Iniciativa. 15.

Persistência. 16. Domínio. 17. Interêsse pelas pessoas. 18 . Lealdade com os homens. 19. Honestidade geral. 20.

Estabilidade emocional. 21. Temperamento. 22. Paciência. 23. Aptidão para as emergências. 24. Aptidão para ensinar. 25. Aptidão para chefiar. 26. Popularidade. 27. Habilidade para delegar responsabilidades.

28. Asseio no vestir. 29. Saúde.

30. Fidelidade à companhia.

31. Aptidão para o trabalho administrativo. 32. Pêso. 33. Altura.

Pedimos a cada supervisor que avaliasse a importância de cada um dos traços em uma escala de cinco pontos. Assinalando o grau $1,2,3,4$, ou 5 com um $X, 0$ avaliador estaria considerando o traço como depreciável, escassamente significativo, de regular

\footnotetext{
1 Realizada com industriários que frequentavam a War Training Class: ocupavam todos postos administrativos e de supervisão em indústria de guerra. Citada no livro de Maier, N.R.F.
Psicologia industrial.
} 
importância, muito importante ou de extrema importância à supervisão, respectivamente.

A pedido dos próprios supervisores, foi mimeografada a lista de traços para que cada um fizesse a sua própria graduação, permitindo-nos, posteriormente, tirar uma média dos graus, em cada traço.

Após tais observações, foram situados os principais aspectos de um processo de seleção, a saber: entrevistas, testes de conhecimentos: teóricos e/ou práticos, como também exames médicos e psicológicos.

Aproveitamos a ocasião para dar esclarecimentos sôbre o exame técnico psicológico, seus objetivos e seu alcance.

Salientamos, em seguida, a questão de teste na nossa pesquisa: escolha da bateria e sua aplicação.

Para tranqüilidade do pessoal frisamos bem que os resultados seriam tratados dentro de todo rigor ético.

Acrescentamos, no entanto, que tais resultados só seriam dados em têrmos de grupo e individualmente àqueles que se interessassem em conhecer os seus próprios.

Finalizando pedimos-lhes todo empenho e colaboração no trabalho e marcamos, para a manhã seguinte, a segunda reunião.

Alguns aspectos importantes gostaríamos de ressaltar dentro de uma análise da reunião $\mathbf{A}$.

Percebemos que, apesar da acentuada participação e centenas de perguntas formuladas a respeito da pesquisa, perduraram os seguintes problemas: associação do nosso trabalho com o do Grupo de Administração de Salários, ${ }^{2}$ havendo nisso muita preocupação, e até mesmo desconfiança, de que nossos resultados iriam influir na análise de classificação de cargos dos supervisores, vindo a prejudicá-los salarialmente.

Perguntavam: "por que, então, êste trabalho está sendo iniciado agora, ao mesmo tempo que o do Grupo de

Administração de Salários?"

Tentou-se, por todos os meios, esclarecer a situação.

Mas, apesar de tôdas as explicações a respeito do sigilo e do aspecto confidencial da pesquisa, pudemos constatar que, lamentàvelmente, a desconfiança permaneceu. Chegaram mesmo a afirmar que estávamos "pregando no deserto" porque a maior parte do pessoal, no fim de todo 0 trabalho, quando sair a classificação de cargos, colocará a culpa da má classificação na nossa pesquisa.

Portanto, temem ser prejudicados e abrigam suspeitas de que não lhes falamos sôbre os reais objetivos.

Apesar de tudo isto, houve um comparecimento de $96 \%$ do pessoal à reunião $\mathrm{B}$, para realizarem os testes, num total de 318 supervisores.

\subsection{Aplicação da bateria fatorial - Reunião B}

No final da reunião A, já esclarecidos os objetivos e a metodologia da pesquisa, os supervisores foram convocados para uma segunda reunião.

0 objetivo específico desta, seria a realização dos testes cujas sessões foram feitas em um auditório com cadeiras de braço.

Antes de se iniciar a aplicação dos mesmos foi distribuído a cada participante um número, que serviria como única identificação a ser escrita.

Pela análise dos dados pessoais dos participantes, verificamos que a maior parte dos supervisores está afastada dos bancos escolares pelo menos há 10 anos, sendo que a grande maioria nunca havia sido submetida a exames psicológicos de lápis-e-papel. A ansiedade e tensão nesta situação provocariam, naturalmente, uma fadiga maior que a normal. Daí, decidiu-se realizar a sessão de testes com dois intervalos.

Começamos com a aplicação do fator N, por se tratar de um teste que mede uma atividade que os supervisores executam rotineiramente em seu trabalho: cálculos. Pelo fato de a atividade em si não trazer problemas, possibilitou ainda que os supervisores se acostumassem com um trabalho cronometrado.

A ordem de aplicação, portanto, foi a seguinte:

Fator $\mathbf{N}$ (numérico). Fator $\mathbf{P}$ (percepção). Fator S (espacial). (intervalo). Fator $\mathbf{R}$ (raciocínio). Fator $\mathbf{V}$ (compreensão verbal). Fator $\mathbf{W}$ (fluência verbal).

(intervalo). Fator G (inteligência geral).

Pela grande participação e pela boa vontade demonstrada pelos supervisores nesta reunião, podemos considerar que algo de positivo foi conseguido: uma crescente confiança nos propósitos da pesquisa.

Após a aplicação, os testes foram corrigidos pela própria equipe de psicólogos dentro das técnicas previstas.

\subsection{Avaliação de desempenho na função}

Tomando os resultados obtidos nos testes e na entrevista, precisávamos ainda conhecer o desempenho dos supervisores em suas funções para que pudéssemos estabelecer comparações entre aquêles

- Descriçåo e avaliaçăo dos cargos de supervisẩo e implantaçǎo de uma polític salarial, ora em andamento na emprêsa. 
resultados e os dados de êxito dos mesmos indivíduos em seu trabalho.

Para se medir êste desempenho foi elaborada uma ficha de avaliação em que constavam os seguintes fatôres:

1. Qualidade do trabalho. 2. Quantidade de trabalho. 3. Senso de responsabilidade. 4. Imaginação. 5. Iniciativa. 6. Sociabilidade. 7. Aptidão para chefiar. 8. Aptidão para ensinar. 9. Aptidão para aprender. 10. Segurança. 11. Conhecimento do trabalho. 12. Desenvolvimento pessoal. 13. Avaliação do pessoal.

Pedimos a cada chefe que avaliasse, nestes fatôres, os supervisores subordinados seus, numa escala de cinco pontos.

Para diminuir a subjetividade do julgamento procuramos dar uma definição clara de cada fator e tomamos todo o cuidado para que as avaliações se fizessem nas melhores condições. Para isso explicamos, detalhadamente, em entrevista com cada chefe, a técnica do merit-rating, prevenindo-os contra os erros freqüentes. Além disso, deixamos com cada um dêles, um manual de avaliação que foi elaborado, especialmente, para orientá-los no trabalho.

Como a avaliação, por meio de juízes é sempre carregada de subjetivismo, julgamos oportuno utilizar, alguns meses depois, uma segunda ficha de avaliação que tivesse o mesmo objetivo da primeira, variando, apenas, a sua forma.

Pedíamos, desta vez, uma apreciação global do supervisor no desempenho de sua função, também numa escala de cinco pontos.

Pretendíamos comparar as duas avaliações para ver a conveniência de se adotar os resultados de uma ou os da outra, ou a média das duas avaliações. Optamos, finalmente, pela média das duas.

\subsection{Entrevista}

Por meio da entrevista tentamos analisar o indivíduo quanto ao seu êxito no cargo de supervisão. Este resultado seria, de certo modo, uma avaliação do supervisor, a qual poderia ser comparada e correlacionada diretamente com critérios valorativos conseguidos por outras fontes.

Para possibilitar esta comparação apresentamos os resultados da entrevista em forma numérica, sendo avaliados, por ela, os seguintes aspectos, numa escala de cinco pontos, conforme orientação de Miguel Signam:

atividade; sociabilidade; adaptação ao cargo; qualificação geral como supervisor.

Obviamente, as entrevistas possibilitaram resultados muito mais ricos. Tôdas elas foram realizadas por um único entrevistador para assegurar a uniformidade do critério, sendo tomadas tôdas as precauções para que se conseguisse uma atitude, a mais favorável possível, por parte dos supervisores. Ressaltamos, especialmente, o aspecto confidencial das mesmas.

Iniciávamos as entrevistas situando seu objetivo: interêsse da emprêsa em conhecer os problemas e dificuldades que encontram os supervisores de nível médio em sua função e a forma de superá-los. $E$, como as entrevistas eram realizadas após a aplicação dos testes fatoriais, o que foi para muitos uma experiência completamente nova, consideramos de suma importância conhecer os sentimentos dos supervisores a respeito da situação vivida, pedindo a cada um que falasse sôbre a mesma. Pudemos ainda estudar a variabilidade das respostas de indivíduo para individuo e, a partir delas, perceber até que ponto nossos objetivos foram compreendidos, aproveitando-se a ocasião para reafirmá-los e tentar interessar os supervisores pelo bom desenvolvimento da pesquisa.

Passávamos, depois, aos seguintes temas:

a) histórico funcional do supervisor;

b) cargo e trabalho atual;

c) qualidades que deve possuir o supervisor médio para desempenho da função;

d) dificuldades que encontra em seu trabalho;

e) dificuldades quanto ao treinamento dos operários;

f) dificuldades quanto à avaliação de desempenho dos operários;

g) dificuldades quanto à organização do trabalho.

Este esquema não foi rígido, mas, orientamo-nos por êle, sendo que cada entrevista desenvolveu-se de uma forma tôda particular. Geralmente, decorridos os primeiros minutos, os supervisores sentiam-se mais à vontade para falar de seus problemas profissionais a um ouvinte que se mostrava atencioso e interessado. Alguns indivíduos, no entanto, manifestaram mais dificuldades para se expressarem e perdiam-se ao apresentarem justificativas dos problemas encontrados ou ao fazer observações superficiais sôbre os temas abordados.

A duração da entrevista variava em tôrno de uma hora.

Não resta dúvida que das entrevistas pudemos obter dados interessantes em muitos sentidos. Certamente serviram

- e para isto foram introduzidas na pesquisa para que o entrevistador qualificasse os entrevistados como supervisores. Mas, serviram também para compreender melhor as funções, as qualidades e as dificuldades do supervisor médio no seu trabalho. 
Dos dados obtidos 0 entrevistador pôde classificar - supervisor dentro do esquema já estabelecido. Ao mesmo tempo, pôde captar indícios que Ihe permitiu perceber o maior ou menor sucesso do sujeito em seu cargo de supervisão. 0 indivíduo com escassas aptidões para seu cargo, normalmente, esbarrou com certos problemas, ou se mostrou cego para

outros, advindo daí

insatisfações.

0 entrevistador, ao longo das entrevistas, pôde ainda perceber, de uma forma mais clara, a situação específica de cada área de trabalho $\mathrm{e}$ estabelecer uma relação com a situação em que se encontra o supervisor, podendo prever daí suas possibilidades de adaptação.

\section{RESULTADOS OBTIDOS}

Apresentamos os resultados em gráficos e em tabelas, onde transcrevemos as médias e os desvios-padrão. Para atender aos nossos objetivos temos tabelas referentes à população total como também resultados separados dos supervisores técnicos, dos supervisores não técnicos e, finalmente, os da população distribuída pelos cargos. Complementando, apresentamos tabelas com os resultados dos agrupamentos com características específicas. Em continuação temos os gráficos das distribuições dos resultados nos testes fatoriais:

1. Comparação das distribuições dos resultados dos técnicos com não técnicos.

2.0 Comparação das distribuição dos resultados pelos diferentes cargos com a distribuições dos resultados da população.

\subsection{Bateria fatorial}

\subsubsection{População total:} $N=318$
TABELA 4

Médias e desvios-padrão dos fatóres na população total

\begin{tabular}{c|r|r}
\hline \multirow{2}{*}{ Fatôres } & \multicolumn{1}{|c|}{$\mathbf{M}$} & \multicolumn{1}{|c}{$\mathrm{S}$} \\
\cline { 2 - 3 } $\mathrm{G}$ & 41,24 & 13,33 \\
$\mathrm{~N}$ & 25,33 & 8,79 \\
$\mathrm{~S}$ & 8,28 & 5,15 \\
$\mathrm{R}$ & 8,50 & 4,47 \\
$\mathrm{~V}$ & 32,24 & 15,68 \\
$\mathrm{~W}$ & 30,02 & 12,50 \\
$\mathrm{P}$ & 10,02 & 6,35 \\
\hline
\end{tabular}

3.1.2 Segundo a escolaridade:
Comparando os resultados dos grupos técnicos e não técnicos com os resultados de população. total notamos grande vantagem do primeiro sôbre o último. A variabilidade do grupo técnico é sempre inferior ao não técnico, demonstrando maior homogeneidade dêste grupo.

\subsubsection{Segundo os cargos:}

Estudando cada fator segundo a distribuição dos examinando pelos seus cargos, encontramos os seguintes resultados:

TABELA 5

Médias e desvios-padrão dos fatôres nos grupos técnicos e não técnicos

\begin{tabular}{|c|c|c|c|c|}
\hline \multirow{2}{*}{ Fatôres } & \multicolumn{2}{|c|}{$\begin{array}{l}\text { Técnico } \\
\mathbf{N}=116\end{array}$} & \multicolumn{2}{|c|}{$\begin{array}{l}n / T \text { écnico } \\
N=202\end{array}$} \\
\hline & $\mathbf{M}$ & $\mathbf{s}$ & $\mathbf{M}$ & $\mathbf{S}$ \\
\hline $\mathbf{G}$ & 51,58 & 6,25 & 35,30 & 12,68 \\
\hline $\mathbf{N}$ & 28,64 & 6,69 & 23,44 & 9,25 \\
\hline $\mathbf{s}$ & 10,88 & 5,22 & 6,78 & 4,48 \\
\hline $\mathbf{R}$ & 11,75 & 3,20 & 6,65 & 4,01 \\
\hline $\mathbf{V}$ & 42,71 & 9,41 & 26,22 & 15,42 \\
\hline $\mathbf{w}$ & 38,13 & 10,05 & 25,37 & 11,32 \\
\hline $\mathbf{P}$ & 13,93 & 5,09 & 7,77 & 5,90 \\
\hline
\end{tabular}
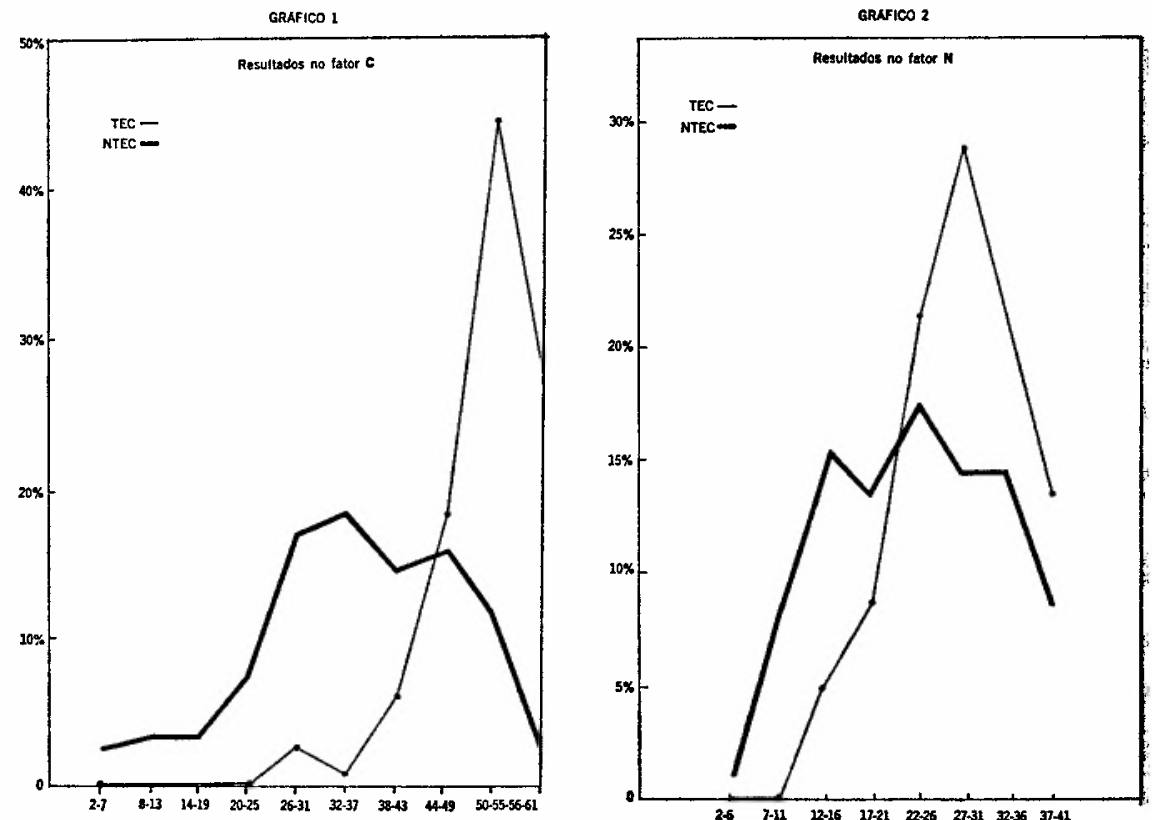

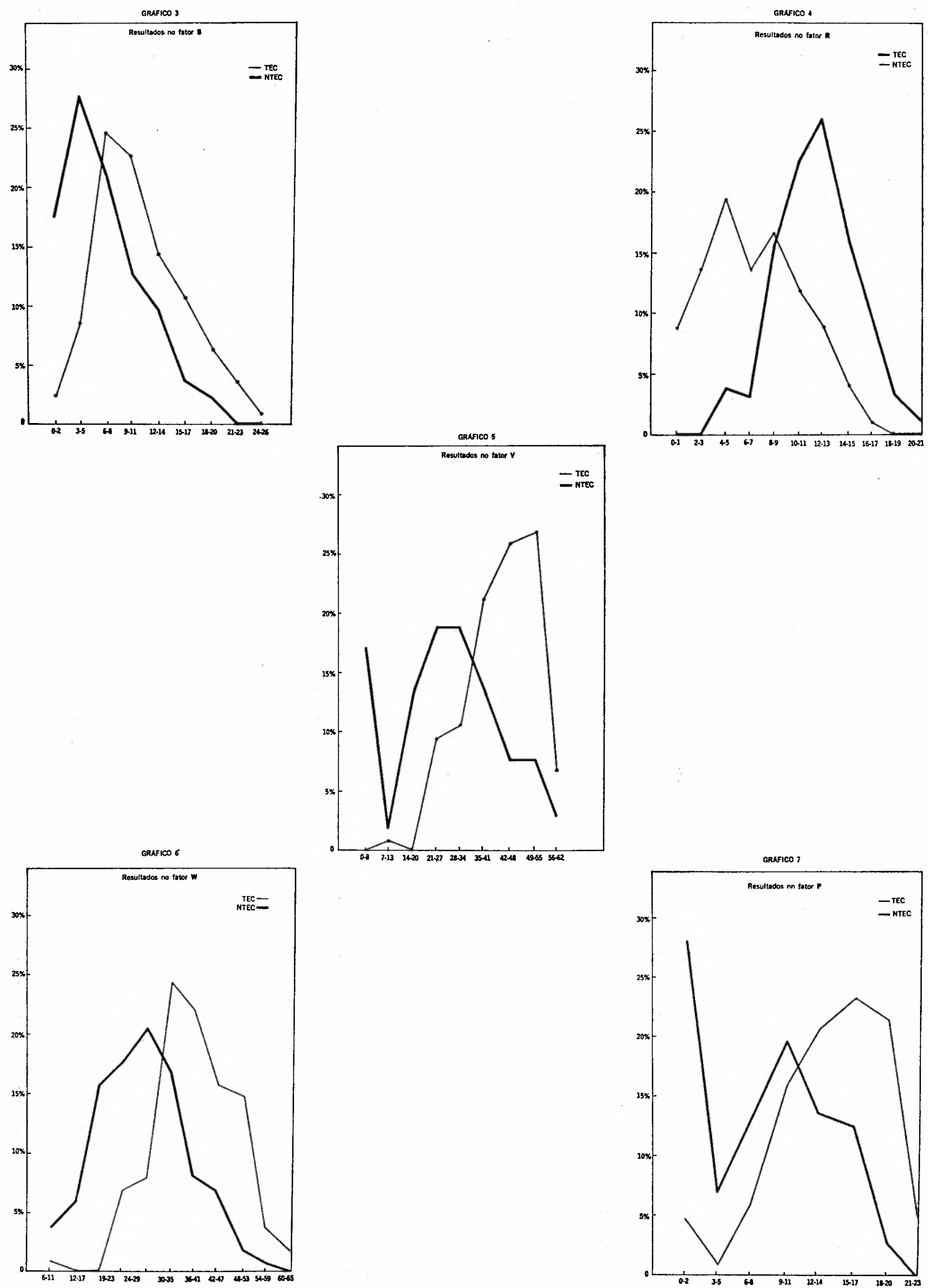

32

Revista de Administração de Emprêsas 
Médias e desvios-padrão do fator $\mathrm{G}$ nos diferentes cargos

\begin{tabular}{l|r|r|r}
\hline \multicolumn{3}{c}{ Fator $G$} \\
\hline Cargos & $\mathrm{N}$ & $\mathrm{M}$ & $\mathrm{S}$ \\
\hline & & & \\
\hline CCM & 29 & 42,10 & $\mathbf{1 4 , 5 1}$ \\
CM & 182 & 38,58 & 14,20 \\
AT & 36 & 49,27 & 7,73 \\
AA & 44 & 42,11 & 9,70 \\
DS & 27 & 47,77 & 7,95 \\
& & & \\
\hline
\end{tabular}

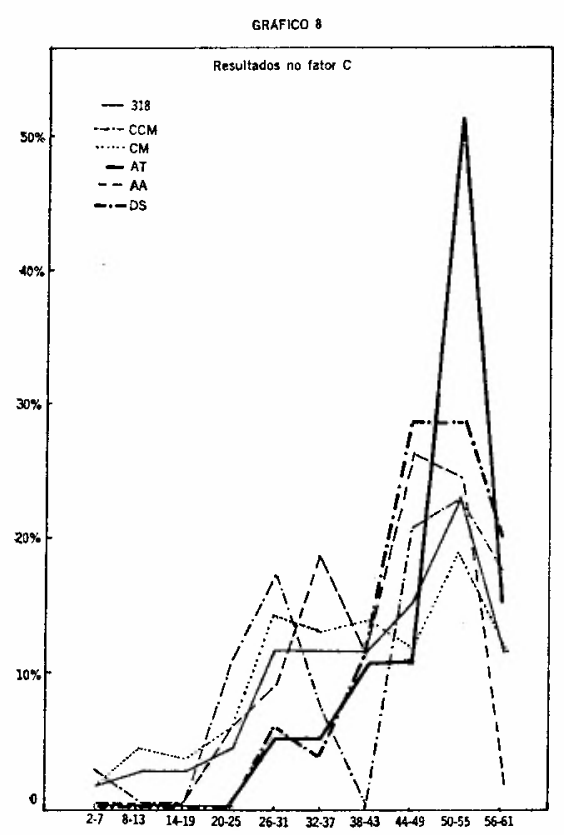

Observamos que no fator $\mathbf{G}$ os resultados pelos cargos apresentam-se bem mais próximos da média da população total do que os resultados pelos grupos técnicos e não técnicos, tomados separadamente. Isto se dá porque os supervisores técnicos estão diluídos pelos cargos.

Os auxiliares técnicos e demais supervisores apresentam melhor rendimento: maior média e menor variabilidade. Devemos observar que o grupo de AT é quase todo formado por supervisores técnicos; os demais supervisores possuem, na maioria, o curso ginasial, o que não é comum em se tratando dos outros cargos.

Também no fator $\mathbf{N}$ verificamos maior média e menor variabilidade no grupo de auxiliares técnicos e no grupo do demais supervisores.
No fator $\mathbf{S}$ as médias pelos cargos são bem próximas. A variabilidade é pràticamente a mesma, com exceção dos auxiliares administrativos, que são mais homogêneos neste

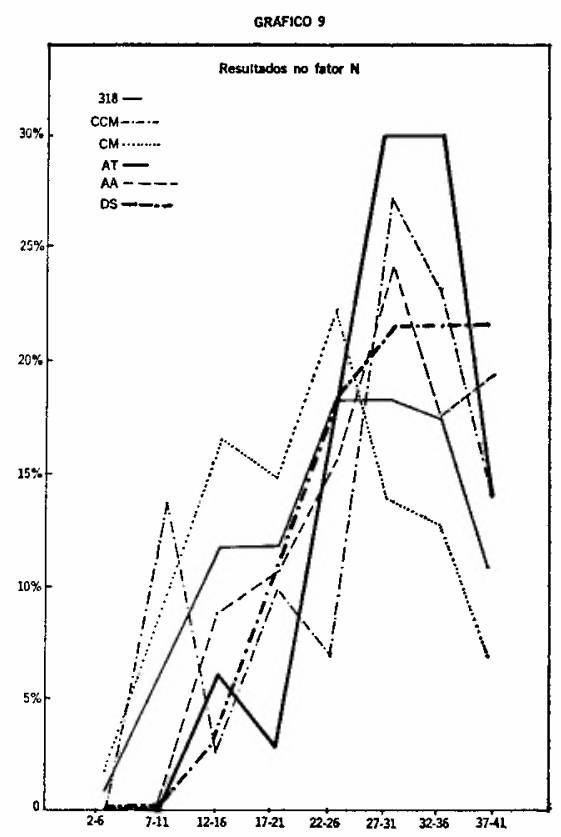

TABELA 7

Médias e desvios-padrão do fator N, nos diferentes cargos

Fator $\boldsymbol{N}$

\begin{tabular}{l|r|c|c}
\hline Cargos & N & M & S \\
\cline { 2 - 4 } CCM & 29 & 27,00 & 9,29 \\
CM & 182 & 22,82 & 8,79 \\
AT & 36 & 29,38 & 6,07 \\
AA & 44 & 28,63 & 7,50 \\
DS & 27 & 29,66 & 7,19 \\
\hline
\end{tabular}

TABELA 8

Médias e desvios-padrão do fator $\mathrm{S}$ nos diferentes cargos

Fator $S$

\begin{tabular}{c|r|r|c}
\hline Cargos & N & M & S \\
\cline { 2 - 3 } CCM & 29 & 7,79 & 5,05 \\
CM & 182 & 8,08 & 5,28 \\
AT & 36 & 9,75 & 5,45 \\
AA & 44 & 7,20 & 3,50 \\
DS & 27 & 9,92 & 5,30 \\
\hline
\end{tabular}

fator, embora com rendimento mais baixo. $O$ fator $\mathbf{S}$ é, realmente, expressão de uma aptidão pouco solicitada para qualquer cargo administrativo. 


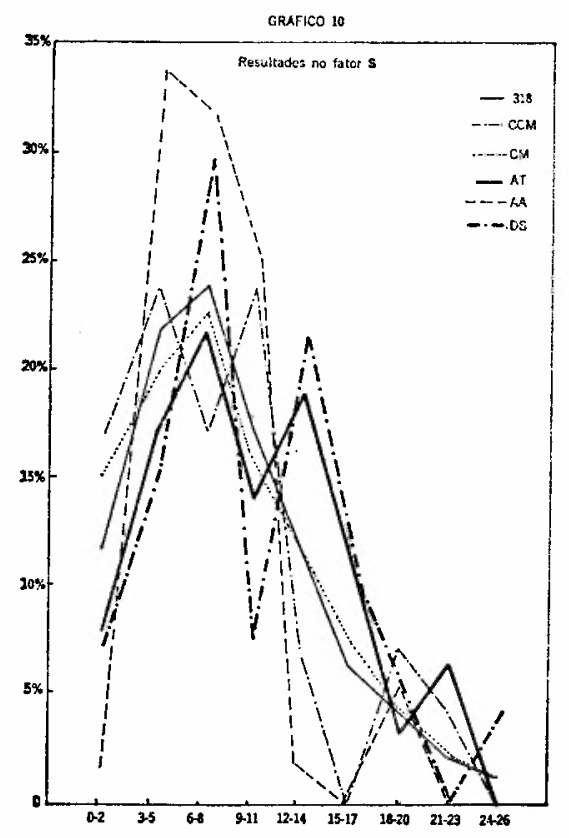

Quanto ao fator $\mathbf{R}$ os auxiliares técnicos apresentam melhor rendimento, o que podemos observar confrontando a média e o desvio-padrăo dêste grupo com os outros.

A mesma observação anterior aplica-se aos fatôres $V, W$ e $P$,
TABELA 9

Médias e desvios-padrão do fator $\mathbf{R}$ nos diferentes carłos

Fator $\boldsymbol{R}$

\begin{tabular}{c|r|r|r}
\hline Cargos & $\mathbf{N}$ & $\mathbf{M}$ & $\mathbf{S}$ \\
\hline CCM & 29 & 9,51 & 3,76 \\
CM & 182 & 7,51 & 5,02 \\
AT & 36 & 10,77 & 2,57 \\
AA & 44 & 9,65 & 3,09 \\
DS & 27 & 9,22 & 3,68 \\
\hline
\end{tabular}
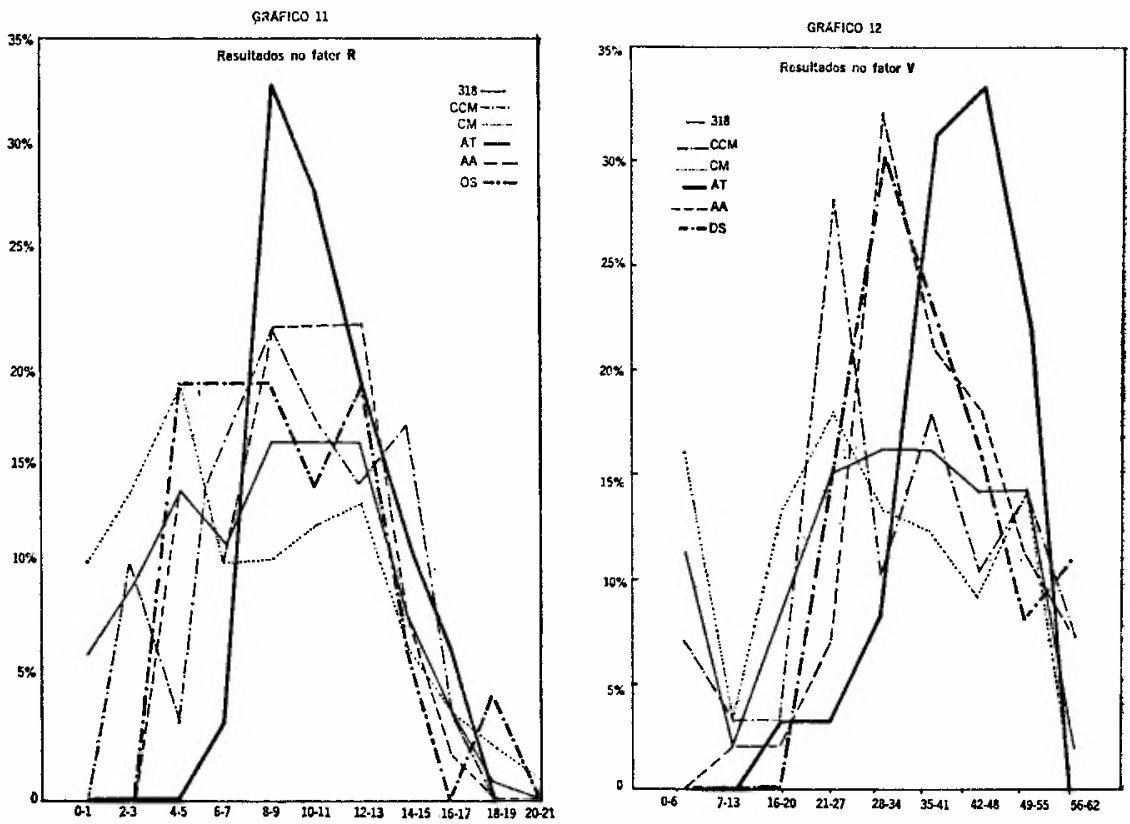

TABELA 10

Médias e desvios-padrío dos fatores $\mathbf{R}$ ○ W nos diferentes cargos

\begin{tabular}{c|r|r|r|r|r}
\hline & & \multicolumn{2}{|c|}{ Fator $V$} & \multicolumn{2}{|c}{ Fator $W$} \\
\hline Cargos & N & M & S & M & S \\
& & & & \\
CCM & 29 & 34,02 & 14,88 & 32,03 & 14,27 \\
CM & 182 & 27,93 & 17,05 & 26,98 & 12,98 \\
AT & 36 & 42,19 & 7,57 & 35,86 & 7,87 \\
AA & 44 & 37,40 & 10,67 & 32,22 & 9,38 \\
DS & 27 & 37,66 & 10,23 & 37,03 & 9,30 \\
& & & & & \\
\hline
\end{tabular}

TABELA 11

Médias e desvios-padráo do fator $\mathbf{P}$ nos diferentes cargos

\begin{tabular}{l|r|r|r}
\hline \multicolumn{3}{|c|}{ Fator $\boldsymbol{P}$} \\
\hline Cargos & $\mathbf{N}$ & $\mathbf{M}$ & $\mathrm{S}$ \\
\hline CCM & & & \\
CM & 29 & 11,04 & 6,13 \\
AT & 182 & 9,28 & 6,68 \\
AA & 36 & 12,43 & 5,25 \\
DS & 44 & 10,43 & 6,23 \\
& 27 & 9,99 & 5,15 \\
\hline
\end{tabular}

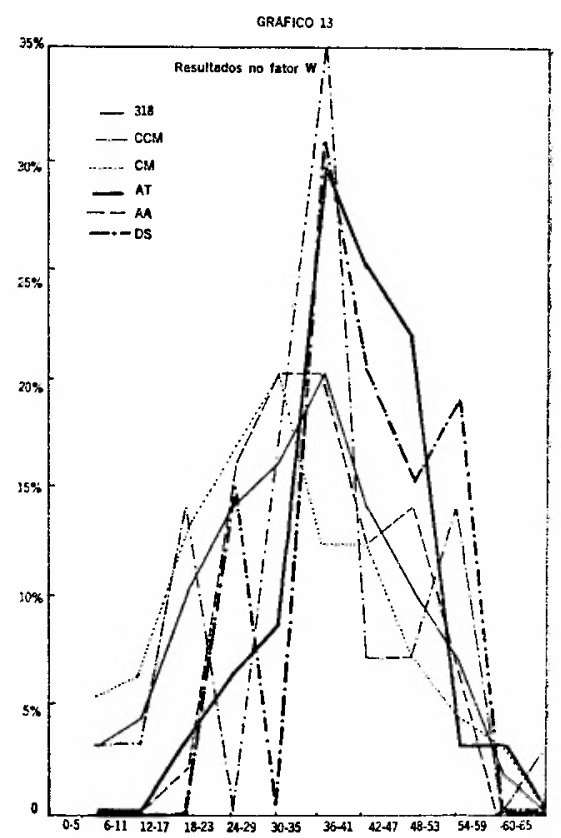




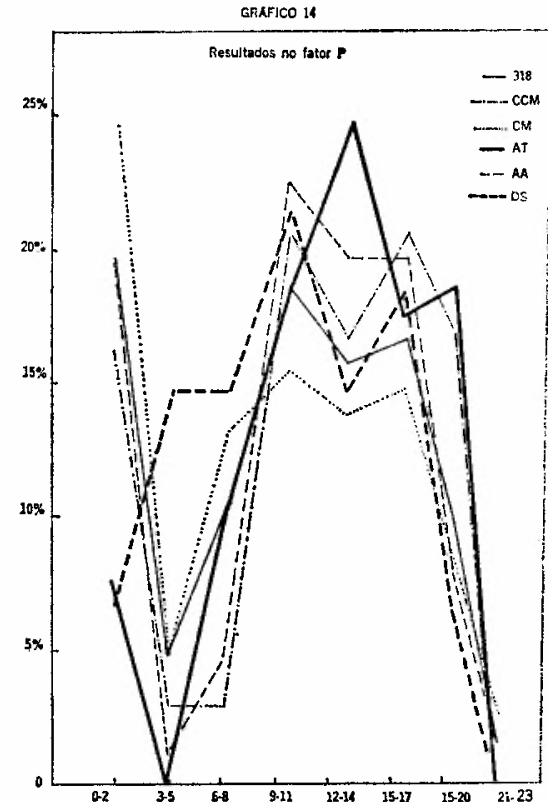

onde a superioridade dos auxiliares técnicos é demonstrada pela maior média e menor variabilidade do grupo.

Em todos os fatôres, com exceção do fator $\mathbf{S}, 0$ rendimento dos contramestres é - menor. Podemos observar que êste grupo apresenta $71 \%$ de supervisores não técnicos, percentagem bastante superior à encontrada nos outros.

\subsection{Avaliação de desempenho na função}

\subsubsection{Segundo a escolaridade}

Observando a tabela 12 encontramos equivalência de resultados na avaliação de desempenho entre os dois grupos: técnico e não técnico.
TABELA 13

Médias o desvios-padrăo dos graus da avaliagro de desempenho nos diferentes cargos

\begin{tabular}{l|r|r|l}
\hline Cargos & N & M & S \\
\cline { 2 - 3 } CCM & 28 & 3,67 & 0,56 \\
CM & 182 & 3,03 & 0,53 \\
AT & 34 & 3,19 & 0,51 \\
AA & 44 & 3,28 & 0,54 \\
DS & 27 & 3,43 & 0,61 \\
\hline
\end{tabular}

\subsubsection{Segundo os cargos}

Nesta tabela observamos que a média dos CCM é superior às médias dos outros grupos, estando mais próxima da média dos demais supervisores.

\subsection{Entrevista}

Dos 318 supervisores em estudo, foram entrevistados 186, o que representa $58 \%$ do total. Não entrevistamos todos, para não alongarmos muito a coleta de dados, sendo levantada uma amostragem por quotas a partir do número de supervisores em cada grupo. Os resultados obtidos são mostrados a seguir.

\subsubsection{Segundo a escolaridade}

Pela tabela 14 não notamos diferença considerável entre os graus alcançados na entrevista pelos dois grupos estudados.
TABELA 14

Médias o desvios-padrăo dos graus da entrevista nos grupos de técnicos o nưo técnicos

\begin{tabular}{l|r|r|r}
\hline \multicolumn{1}{c|}{ Agrupamento } & N & M & S \\
\cline { 2 - 4 } Técnico & 73 & 3,29 & 0,58 \\
n/técnico & 113 & 3,26 & 0,47 \\
\hline
\end{tabular}

TABELA 15

Médias o desvios-padråo dos graus da entrevista nos diferentes cargos

\begin{tabular}{c|c|c|c}
\hline Cargos & N & M & S \\
\cline { 1 - 3 } CCM & 25 & 3,71 & 0,67 \\
CM & 86 & 3,22 & 0,44 \\
AT & 29 & 3,09 & 0,54 \\
AA & 28 & 3,22 & 0,38 \\
DS & 18 & 3,27 & 0,55 \\
\hline
\end{tabular}

TABELA 12

Médias o desvios-padrão dos graus da avaliaģáo de desempenho nos grupos de técnicos e não técnicos

\begin{tabular}{l|l|l|l}
\hline \multicolumn{1}{c|}{ Agrupamento } & N & M & S \\
\hline TÉcnico & 114 & 3,24 & 0,60 \\
n/técnico & 201 & 3,13 & 0,50 \\
\hline
\end{tabular}

\subsubsection{Segundo os cargos}

Observando a tabela 15 notamos que os CCM apresentam resultados, na entrevista, superiores aos outros grupos. Em seguida estão os demais supervisores.

\subsection{Resultados obtidos na avaliação de desempenho na função, nos grupos com características especifficas}


TABELA 16

Medias e desvios-padrio dos graus da avaliação de desempenho nos grupos com características especificas

\begin{tabular}{|c|c|c|c|}
\hline Agrupamentos & $\mathbf{N}$ & $\mathbf{M}$ & $\mathbf{S}$ \\
\hline $\begin{array}{l}\text { 1. Segundo idade (t de } 50 \text { anos) e tempo de compa- } \\
\text { nhia (t de } 20 \text { anos) } \\
\text { 2. Segundo idade (t de } 50 \text { anos) e tempo de super- } \\
\text { visão (t de } 20 \text { anos) } \\
\text { 3. Segundo idade (de } 21 \text { a } 25 \text { anos) e tempo de compa- } \\
\text { nhia (- de } 1 \text { ano) } \\
\text { 4. Segundo idade (de } 21 \text { a } 25 \text { anos) e tempo de super- } \\
\text { visão (- de } 1 \text { ano) } \\
\text { 5. Segundo idade (de } 26 \text { a } 30 \text { anos) e tempo de compa- } \\
\text { nhia (de } 5 \text { a } 10 \text { anos) } \\
\text { 6. Segundo idade (de } 31 \text { a } 35 \text { anos) e tempo de super- } \\
\text { visão (de } 6 \text { a } 10 \text { anos) } \\
\text { 7. Segundo idade (de } 41 \text { a } 45 \text { anos) e tempo de compa- } \\
\text { 8. nhia (t de } 20 \text { anos) } \\
\text { Segundo idade (de } 26 \text { a } 30 \text { anos) e tempo de super- } \\
\text { visão (de } 1 \text { a } 2 \text { anos) }\end{array}$ & $\begin{array}{r}15 \\
7 \\
12 \\
18 \\
20 \\
37 \\
28\end{array}$ & $\begin{array}{l}2,75 \\
2,79 \\
3,07 \\
2,99 \\
3,25 \\
3,19 \\
3,18 \\
3,19\end{array}$ & $\begin{array}{l}0,98 \\
0,62 \\
0,35 \\
0,33 \\
0,35 \\
0,47 \\
0,50 \\
0,51\end{array}$ \\
\hline
\end{tabular}

\section{INSTRUMENTOS ESTATISTICOS}

Como já prevíamos, todos os nossos cálculos foram feitos à mão, e por isto reduzimos bastante a área de nossas pesquisas.

Assim, não nos foi possível esgotar tôdas as possibilidades de cruzamento das variáveis, bem como o contrôle das mesmas em tôdas as situações relevantes. Nosso trabalho seria consideràvelmente enriquecido, se pudéssemos, também, adotar um grupo de contrôle.

Os resultados da bateria fatorial e os da avaliação de desempenho na função, como esperávamos, distribuíram-se como na curva gaussiana (ver gráficos); portanto, adotamos sómente testes paramétricos. As correlações foram calculadas de acôrdo com o método de Bravais Pearson, o que nos permitiu um pequeno estudo fatorial, pelo método de Thurstone.

Para todos os cálculos de significância de médias (testes $t$ ), de percentagens e correlações, adotamos o nível 0,01 de preferência. Os cálculos de análise foram interpretados também neste nivel. Os testes foram unicaudais ou bicaudais, conforme a exigência de nossas hipóteses.

As escalas de avaliação da bateria fatorial foram levantadas em tetrons, os quais foram convertidos em percentis normalizados. Temos escalas para tôda a população e escalas especiais para avaliar o rendimento dos supervisores, de acôrdo com sua formação técnica e/ou não técnica.
Levantamos escalas também, para avaliação do supervisor segundo os cargos.

Os gráficos foram todos feitos em têrmos percentuais para facilitar as comparações.

\section{ANÁLISE E INTERPRETAÇAOO DOS RESULTADOS}

Para analisar os resultados encontrados seguiremos 0 mesmo esquema que temos observado até aqui.

Primeiramente, apresentaremos a análise dos resultados do grupo técnico comparando aos resultados do grupo não técnico.

\section{Em segundo lugar} apresentaremos a análise dos resultados na sua distribuição pelos cargos.

Por último analisaremos alguns aspectos característicos da população e, até mesmo, estudaremos alguns casos individuais.

\section{1}

TABELA 17

Significância das médias dos fatóres entre os grupos de técnicos e não técnicos

\begin{tabular}{c|r|r|r}
\hline Fatôres & Técnico & n/Técnico & \multicolumn{1}{|c}{ T } \\
\hline G & 51,58 & 35,30 & 15,35 \\
N & 28,64 & 23,44 & 5,84 \\
S & 10,88 & 6,78 & 7,19 \\
R & 11,73 & 6,65 & 12,70 \\
V & 42,71 & 26,22 & 11,86 \\
W & 38,13 & 25,37 & 10,45 \\
P & 13,93 & 7,77 & 9,93 \\
& & & \\
\hline
\end{tabular}

\section{2}

TABELA 18

Significáncia das médias entre as duas avaliaçõos de desempenho

\begin{tabular}{l|c|c}
\hline \multicolumn{1}{c|}{ Avaliação de desempenho } & $\mathrm{M}$ & $\mathrm{S}$ \\
\hline \multirow{2}{*}{ Por fatôres } & 3,22 & 0,50 \\
Geral & 3,05 & 0,70
\end{tabular}

$t=4,25>2,58$ 
Interpretando os resultados do teste $\mathbf{t}$ apresentados na tabela 17 , chegamos à conclusão de que as médias do grupo técnico são significativamente superiores às do não técnico em todos os fatôres.

A nossa hipótese foi confirmada, no mínimo ao nível de 0,000001 .
Pela tabela 18, onde fornecemos os resultados do teste $t$ entre as duas avaliações de desempenho na função, verificamos que, realmente, as médias das duas avaliações diferem, significativamente, uma da outra. Isto confirma a nossa hipótese de trabalho e justifica a nossa decisão em utilizar a média das duas avaliações na nossa pesquisa.

\section{3}

TABELA 19

Significância das médias dos graus da avaliação de desempenho entre os grupos de técnicos e não técnicos

\begin{tabular}{l|l|r|c}
\hline \multicolumn{1}{c|}{ Agrupamento } & $\mathrm{N}$ & $\mathrm{M}$ & $\mathrm{S}$ \\
\hline Téenico & 114 & 3,24 & 0,60 \\
n/técnico & 201 & 3,13 & 0,50 \\
\hline & & $t=1,37<2,34$ \\
\hline
\end{tabular}

Pela tabela 19 verificamos que, significativamente dos não na avaliação de desempenho na função, os supervisores técnicos não diferem técnicos. Rejeitamos assim a nossa hipótese de trabalho.

5.4

TABELA 20

Significância das médias dos graus da entrevista entre oo grupos de técnicos e nåo técnicos

\begin{tabular}{l|c|c|c}
\hline \multicolumn{1}{c|}{ Agrupamento } & $N$ & $\mathrm{M}$ & $\mathrm{S}$ \\
\hline Técnico & 73 & 3,29 & 0,58 \\
n/técnico & 113 & 3,26 & 0,47 \\
\hline & $\mathrm{t}=0,37<2,34$
\end{tabular}

Examinando a tabela 20 , onde damos as estatísticas referentes aos graus alcançados na entrevista pelos grupos técnicos e não técnicos, temos um valor $\mathbf{t}=0,37$. Concluímos, então, que nas entrevistas os dois grupos supracitados não apresentam diferença significativa entre os seus resultados; em decorrência rejeitamos a nossa hipótese de trabalho.

\section{5}

TABELA 21

\begin{tabular}{|c|c|c|c|c|}
\hline \multicolumn{5}{|c|}{$\begin{array}{c}\text { Correlaçốes entre os testes fatoriais, Graus da avaliação de desempenho } \\
\text { e entrevista, nos grupos de técnicos e não técnicos }\end{array}$} \\
\hline \multirow{2}{*}{ Fatôres } & \multicolumn{2}{|c|}{ Técnico } & \multicolumn{2}{|c|}{ n/Técnico } \\
\hline & Avaliação & Entrevista & Avaliação & Entrevista \\
\hline $\begin{array}{l}\text { G } \\
N \\
\text { S } \\
R \\
\text { V } \\
\text { W } \\
\text { P }\end{array}$ & $\begin{array}{r}0,10 \\
0,07 \\
0,22 \\
0,07 \\
-0,01 \\
0,13 \\
-0,01\end{array}$ & $\begin{array}{r}0,06 \\
0,02 \\
-0,10 \\
0,26 \\
-0,18 \\
0,25 \\
0,02\end{array}$ & $\begin{array}{l}0,30 \\
0,30 \\
0,28 \\
0,29 \\
0,36 \\
0,38 \\
0,41\end{array}$ & $\begin{array}{r}0,03 \\
-0,01 \\
-0,01 \\
-0,02 \\
0,01 \\
0,04 \\
-0,91\end{array}$ \\
\hline \multicolumn{3}{|c|}{ Av $\times$ Ent $=0,38$} & \multicolumn{2}{|c|}{ Av $\times$ Ent $=0,04$} \\
\hline
\end{tabular}


Na tabela 21 mostramos as correlações entre os testes fatoriais, avaliação de desempenho profissional, e graus da entrevista. Verificamos, aí, que tôdas as correlações são baixas, principalmente no grupo de supervisores técnicos.

Poucas diferem significativamente de zero. No grupo dos supervisores não técnicos as correlações são maiores entre desempenho na função e aptidões. As correlações entre fatôres e graus na entrevista são pràticamente nulas.

A partir das correlações cruzadas entre os resultados dos testes fatoriais e os resultados da avaliação de desempenho, calculamos as saturações fatoriais em dois fatôres para cada um dos dois grupos.

Tivemos a matriz fatorial que apresentamos a seguir:

TABELA 22

Matriz fatorial

\begin{tabular}{|c|c|c|c|c|c|c|}
\hline \multirow{3}{*}{ Aptidões } & \multicolumn{3}{|c|}{ n/Técnicos } & \multicolumn{3}{|c|}{ Técnicos } \\
\hline & \multicolumn{3}{|c|}{ Fatôres } & \multicolumn{3}{|c|}{ Fatôres } \\
\hline & I & II & $\mathbf{s}$ & I & II & $\mathbf{s}$ \\
\hline $\begin{array}{l}\mathbf{G} \\
\mathbf{N} \\
\mathbf{S} \\
\mathbf{R} \\
\mathbf{V} \\
\mathbf{W} \\
\mathbf{P}\end{array}$ & $\begin{array}{l}0,79 \\
0,69 \\
0,60 \\
0,81 \\
0,78 \\
0,76 \\
0,76\end{array}$ & $\begin{array}{r}0,27 \\
0,29 \\
-0,20 \\
0,46 \\
0,07 \\
-0,20 \\
-0,35\end{array}$ & $\begin{array}{l}0,30 \\
0,44 \\
0,60 \\
0,24 \\
0,39 \\
0,39 \\
0,30\end{array}$ & $\begin{array}{l}0,74 \\
0,28 \\
0,56 \\
0,64 \\
0,50 \\
0,46 \\
0,45\end{array}$ & $\begin{array}{r}0,35 \\
0,59 \\
0,21 \\
-0,02 \\
0,03 \\
-0,37 \\
0,40\end{array}$ & $\begin{array}{l}0,33 \\
0,57 \\
0,44 \\
0,59 \\
0,75 \\
0,65 \\
0,44\end{array}$ \\
\hline $\mathbf{A}$ & 0,42 & $-0,24$ & 0,38 & 0,16 & 0,18 & 0,94 \\
\hline
\end{tabular}

Podemos observar que as saturações num fator $\mathbf{G}$ ou fator I, no grupo não técnico, são maiores do que aquelas encontradas no grupo técnico. Passando a observar a coluna $\mathbf{S}$, onde estão relacionadas as contribuições de um fator específico para a variância dos resultados, vemos que no grupo técnico essas contribuições são bem maiores. No desempenho profissional A, esta contribuição eleva-se, no grupo técnico, a 0,94 . Isto vem confirmar a nossa hipótese de trabalho de que o supervisor com formação técnica desempenha as suas funções apelando muito mais para suas aptidões especificas.

Os cursos técnicos são, realmente, de grande importância para o supervisor no seu desempenho funcional, fornecendo-Ihe valiosos instrumentos de trabalho.

Passaremos a analisar, agora, os resultados dos supervisores distribuídos pelos seus cargos.
Na tabela 23-a estão as estatísticas encontradas. A tabela 23-b mostra-nos os resultados dos testes $t$, quando cruzamos os resultados da bateria fatorial.

Na primeira coluna da tabela estão os números das combinações efetuadas. $\mathrm{Na}$ segunda os cargos comparados dois a dois. Para facilidade de consulta os cargos que apresentaram média superior, na maioria dos fatôres, foram colocados à esquerda, em grifo estão os 27 resultados significativos ao nivel de 0,05 , isto é, a partir do valor $\mathbf{t}=$ $=1,96$; ao nível de 0,01 tivemos 17 diferenças significativas. Vemos, na tabela 23-a que os AT mostram-se superiores aos outros em quase todos os fatôres. Na tabela 23-b as suas médias apresentam diferenças significativas em quase todos os cruzamentos: são superiores aos CCM nos fatôres $\mathbf{G}, \mathbf{N}, \mathbf{R}, \mathbf{V}, \mathbf{W}$ e $\mathbf{P}$ (linha 5), são superiores aos $A A$ nos fatôres $\mathbf{G}, \mathbf{S}$ e $\mathbf{V}$ (linha 8). 
Comparados aos DS os AT não são significativamente superiores (linha 9). Os demais supervisores não são significativamente superiores aos chefes-contramestres em nenhum fator, (linha 4); entretanto, são superiores aos contramestres nos fatôres $\mathbf{G}, \mathbf{N}$, $R, \mathbf{V}$ e W (linha 7).

Cotejados com os auxiliares administrativos são superiores nos fatores $\mathbf{G}, \mathbf{S}$ e $\mathbf{W}$ (linha 10 ). Nos demais cargos encontramos diferenças significativas entre as médias dos testes fatoriais quando comparamos

chefe-contramestre e contramestre nos fatores $\mathbf{N}$ e R (linha 1). Os chefes-contramestres não diferem dos auxiliares administrativos (linha 3) e nem dos demais supervisores (linha 4).

5.6.a)

TABELA 23/a

Médias e desvios-padrão dos fatóres nos diferentes cargos

\begin{tabular}{|c|c|c|c|c|c|c|c|c|c|c|}
\hline \multirow{2}{*}{ Fatôres } & \multicolumn{2}{|c|}{$\begin{array}{c}C C M \\
N=29\end{array}$} & \multicolumn{2}{|c|}{$\begin{array}{l}\mathrm{CM} \\
\mathrm{N}\end{array}$} & \multicolumn{2}{|c|}{$\stackrel{A T}{N=36}$} & \multicolumn{2}{|c|}{$\stackrel{A A}{N=} 44$} & \multicolumn{2}{|c|}{$\stackrel{D S}{N=27}$} \\
\hline & $\mathbf{M}$ & $\mathbf{s}$ & $\mathbf{M}$ & $\mathbf{s}$ & $\mathbf{M}$ & $\mathbf{S}$ & $\mathbf{M}$ & $\mathbf{S}$ & $\mathbf{M}$ & $\mathbf{S}$ \\
\hline G & 42,10 & 14,51 & 38,58 & 14,20 & 49,27 & 7,73 & 42,11 & 9,70 & 47,77 & 7,95 \\
\hline $\mathbf{N}$ & 27,00 & 9,29 & 22,82 & 8,79 & 29,38 & 6,07 & 28,68 & 7,50 & 29,66 & 7,19 \\
\hline $\mathbf{S}$ & 7,79 & 5,05 & 8,08 & 5,28 & 9,75 & 5,45 & 7,20 & 3,50 & 9,92 & 5,30 \\
\hline $\mathbf{R}$ & 9,51 & 3,76 & 7,51 & 5,02 & 10,77 & 2,57 & 9,65 & 3,09 & 9,22 & 3,68 \\
\hline $\mathbf{V}$ & 34,03 & 14,88 & 27,93 & 17,05 & 42,19 & 7,57 & 37,40 & 10,67 & 37,66 & 10,23 \\
\hline $\mathbf{w}$ & 32,03 & 14,27 & 26,98 & 12,98 & 35,86 & 7,87 & 32,22 & 9,38 & 37,03 & {$[9,30$} \\
\hline $\mathbf{P}$ & 11,04 & 6,13 & 9,28 & 6,68 & 12,43 & 5,25 & 10,43 & 6,23 & 9,99 & 5,15 \\
\hline
\end{tabular}

$5.6 . b)$

TABELA $23 / b$

Significancia das médias dos fatôres entre os diferentes cargos combinados - Valores $\mathrm{t}$ -

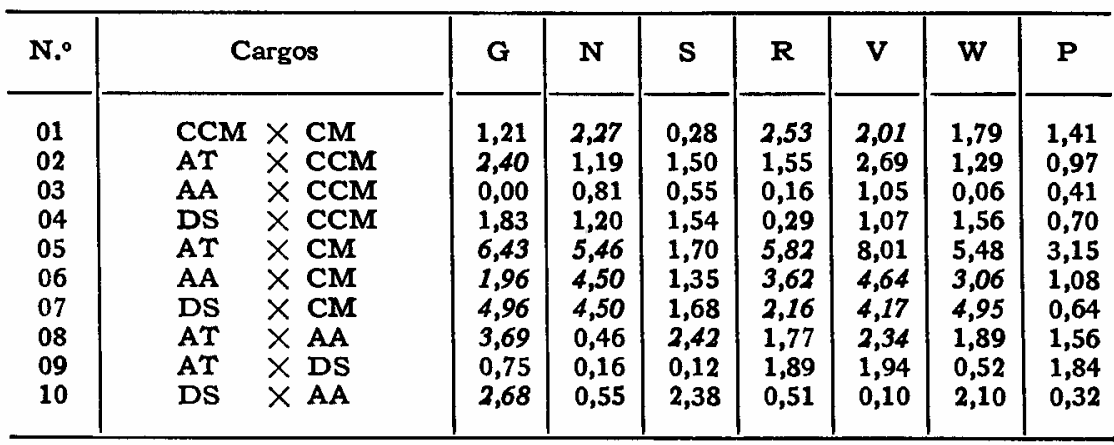

5.7.a)

TABELA 24

Médias o desvios-padrão dos sraus da avalią̧a do desempenho - da entrevista nos diferentes cargos

\begin{tabular}{c|c|c|c|c|c|c}
\hline \multirow{2}{*}{ Cargos } & \multicolumn{3}{|c|}{ Avaliação de desempenho } & \multicolumn{3}{|c}{ Entrevista } \\
\cline { 2 - 3 } & \multicolumn{1}{c|}{$N$} & $\mathrm{~N}$ & $\mathrm{~S}$ & $\mathrm{~N}$ & $\mathrm{M}$ & $\mathrm{S}$ \\
\hline & & & & & \\
\hline CCM & 28 & 3,67 & 0,56 & 25 & 3,71 & 0,67 \\
CM & 182 & 3,03 & 0,53 & 86 & 3,22 & 0,44 \\
AT & 34 & 3,19 & 0,51 & 29 & 3,09 & 0,54 \\
AA & 44 & 3,28 & 0,54 & 28 & 3,22 & 0,38 \\
DS & 27 & 3,43 & 0,61 & 18 & 3,27 & 0,55 \\
\hline
\end{tabular}

Analisando os resultados da avaliação de desempenho na função e os graus da entrevista, levantamos dois quadros: um das estatísticas encontradas e outro de valôres do teste $t$, nas diversas combinações entre os grupos tomados dois a dois.

Pela análise da variância rejeitamos a hipótese de que os grupos pertençam a uma mesma população nestes dois aspectos.

Analisando as médias vemos que os chefes-contramestres apresentaram médias superiores aos outros tanto na entrevista como na avaliação de desempenho funcional (tabela 24).

Estas diferenças não são significativas apenas quando os chefes-contramestres são comparados aos demais supervisores (linha 4).

Os demais supervisores e os auxiliares administrativos são significativamente superiores 
aos contramestres no

desempenho funcional (linhas

6 e 7) (tabela 25).

Assim sendo, podemos admitir que os chefes-contramestres são mais ajustados e mais

valorizados; e podemos admitir também que ajustamento $e$ desempenho na função são interligados de alguma forma. A correlação entre resultados da avaliação do desempenho na função e graus da entrevista no grupo de CCM foi das mais altas: 0,31. Esta correlação é significativa ao nível de 0,01 . No grupo de AT a correlação foi de 0,46 , significativa com $22 \%$ de variância comum.

5.8

5.7.b)

TABELA 25

Significancia das médias dos graus da avaliação de desempenho o da entrevista entre os diferentes cargos combinados

\begin{tabular}{l|c|c|c}
\hline N. & Cargos & $\begin{array}{c}\text { Avaliação de } \\
\text { desempenho } \\
t\end{array}$ & $\begin{array}{c}\text { Entrevista } \\
t\end{array}$ \\
\hline 01 & CCM $\times$ CM & 5,81 & 3,50 \\
02 & CCM $\times$ AT & 3,69 & 3,87 \\
03 & CCM $\times$ AA & 3,00 & 3,26 \\
04 & CCM $\times$ DS & 1,60 & 2,44 \\
05 & CM $\times$ AT & 1,77 & 1,18 \\
06 & AA $\times$ CM & 2,77 & 0,00 \\
07 & DS $\times$ CM & 3,33 & 0,38 \\
08 & AT $\times$ AA & 0,81 & 1,08 \\
09 & AT $\times$ DS & 1,71 & 1,12 \\
10 & AA $\times$ DS & 1,07 & 0,35 \\
\hline
\end{tabular}

TABELA 26

Correlações cruzadas entre os resultados da bateria fatorial, avaliação no desempenho e graus da entrevista.

\begin{tabular}{|c|c|c|c|c|c|c|c|c|c|c|}
\hline \multirow{2}{*}{ Fatôres } & \multicolumn{2}{|c|}{ CCM } & \multicolumn{2}{|c|}{ CM } & \multicolumn{2}{|c|}{ AT } & \multicolumn{2}{|c|}{ AA } & \multicolumn{2}{|c|}{ DS } \\
\hline & Avaliação & Entrevista & Avaliação & Entrevista & Avaliação & Entrevista & Avaliação & Entrevista & Avaliação & Entrevista \\
\hline $\mathbf{G}$ & 0,12 & 0,20 & 0,13 & 0,01 & 0,15 & 0,08 & $-0,07$ & $-0,17$ & 0,32 & 0,14 \\
\hline $\mathbf{N}$ & $-0,01$ & 0,17 & 0,35 & 0,06 & $-0,16$ & 0,02 & $-0,14$ & $-0,22$ & 0,14 & $-0,24$ \\
\hline $\mathbf{S}$ & $-0,02$ & $-0,02$ & 0,30 & $-0,14$ & 0,37 & 0,09 & 0,15 & $-0,02$ & 0,25 & 0,17 \\
\hline $\mathbf{R}$ & $-0,09$ & 0,20 & 0,25 & 0,04 & 0,14 & 0,07 & 0,13 & $-0,21$ & 0,18 & $-0,05$ \\
\hline V & 0,15 & $-0,28$ & 0,82 & 0,08 & 0,04 & 0,01 & 0,23 & $-0,21$ & 0,30 & $-0,25$ \\
\hline$w$ & 0,27 & 0,47 & 0,24 & 0,01 & 0,36 & 0,52 & 0,30 & $-0,20$ & 0,34 & 0,08 \\
\hline $\mathbf{P}$ & $-0,13$ & $-0,05$ & 0,21 & $-0,14$ & $-0,07$ & $-0,02$ & $-0,20$ & $-0,20$ & 0,30 & $-0,04$ \\
\hline
\end{tabular}

Aval. $\times$ Ent. $=$ Aval. $\times$ Ent. $=$

Aval. $\times$ Ent. $=\quad$ Aval. $\times$ Ent. $=$

Aval. $\times$ Ent. $=$

$$
=0,31
$$

$=0,20$

$=0,46$

$=0,28$

$=0,23$

Examinando a tabela 26 , onde mostramos as correlações cruzadas entre rendimento nos fatôres, avaliação de desempenho na função e os graus na entrevista distribuídos pelos cargos, encontramos coeficientes bastante baixos. A maioria das correlações não difere significativamente de zero. As correlações grifadas são as maiores - acima de 0,25 .

Os resultados da avaliação de desempenho na função, conforme nossa hipótese, deveriam apresentar correlações maiores com os fatôres. 0 grupo dos contramestres e os demais supervisores são aquêles que chegaram às maiores correlações entre desempenho e fatôres.

Os auxiliares técnicos, os auxiliares administrativos e os

5.9.a)

TABELA 27

Resultados dos agrupamentos de acôrdo com a idade

\begin{tabular}{|c|c|c|c|c|c|c|}
\hline \multirow{2}{*}{$\begin{array}{l}\text { Agrupamentos } \\
\text { Idade }\end{array}$} & \multicolumn{3}{|c|}{ Avaliação de desempenho } & \multicolumn{3}{|c|}{ Entrevista } \\
\hline & $\mathbf{N}$ & $\mathbf{M}$ & $\mathbf{s}$ & $\mathbf{N}$ & $\mathbf{M}$ & $\mathbf{s}$ \\
\hline 1 & & & & & & \\
\hline$\left(\begin{array}{lll}21 & \text { a } & 25\end{array}\right)$ & 25 & 3,02 & 0,49 & 16 & 3,19 & 0,64 \\
\hline $\begin{array}{c}(26 \text { a } 30) \\
3\end{array}$ & 58 & 3,21 & 0,48 & 32 & 3,33 & 0,57 \\
\hline$\left(\begin{array}{lll}31 & \text { a } \\
4\end{array}\right.$ & 56 & 3,31 & 0,56 & 37 & 3,22 & 0,49 \\
\hline$\left(\begin{array}{l}36 \underset{5}{a} 40) \\
\text { a }\end{array}\right.$ & 52 & 3,36 & 0,50 & 33 & 3,27 & 0,54 \\
\hline $\begin{array}{c}(41 \text { a } \\
6 \\
6\end{array}$ & 48 & 3,20 & 0,57 & 29 & 3,24 & 0,36 \\
\hline$(46$ a 50$)$ & 37 & 3,04 & 0,62 & 22 & 3,28 & 0,53 \\
\hline$(+$ de 50$)$ & 39 & 2,86 & 0,65 & 17 & 3,38 & 0,57 \\
\hline
\end{tabular}


Talvez a hipótese de linearidade não fôsse a mais adequada neste caso. Os cálculos de correlações múltiplas nos dariam uma série de outras informações. Salientamos, mais uma vez, que reduzimos nossos cálculos àqueles que tínhamos possibilidades de executar sem computadores.

Comparando na tabela 27 a avaliação de desempenho com a idade do supervisor notamos que os agrupamentos de supervisores idosos - 6 e 7 apresentam a menor nota. Os agrupamentos de jovens -3 e 4 - são os melhores.

0 agrupamento 3 é

significativamente superior aos agrupamentos 1, 6 e 7 (tabela 28-t-1). 04 é também significativamente superior aos agrupamentos 1, $6 \mathrm{e} \mathrm{7;} \mathrm{isto} \mathrm{é,}$ melhor do que o agrupamento jovem sem experiência e melhor do que o idoso, apesar de sua experiência.

Ainda na tabela 27 vemos que o agrupamento 7 alcançou a maior média nos graus da entrevista.

Comparando as médias de entrevista na tabela 28-t-2, vemos que as diferenças observadas não são significativas. No entanto notamos que há maior tendência do agrupamento idoso mostrar-se mais ajustado.

5.9.b)
Observando a tabela 29 percebemos que os melhores resultados foram conseguidos pelo agrupamento 4 , enquanto 0 1 obteve os menores resultados nas duas avaliações.
Pela tabela 30-t-1, vemos que o agrupamento 1 é significativamente inferior aos agrupamentos 4, 5 e 6; êste último é significativamente superior ao 7.

\section{$5.10 . a)$}

6. TABELA 29

Resultados dos agrupamentos de acordo com o tempo de companhia

\begin{tabular}{|c|c|c|c|c|c|c|}
\hline \multirow{2}{*}{$\begin{array}{c}\text { Agrupamentos } \\
\text { Tempo de companhia }\end{array}$} & \multicolumn{3}{|c|}{ Avaliação de desempenho] } & \multicolumn{3}{|c|}{ Entrevista } \\
\hline & $\mathbf{N}$ & $\mathbf{M}$ & $\mathbf{s}$ & $\mathbf{N}$ & $\mathbf{M}$ & $\mathbf{s}$ \\
\hline$\left(\begin{array}{c}1 \\
-1 \text { ano })\end{array}\right.$ & 13 & 2,91 & 0,44 & 7 & 3,04 & 0,60 \\
\hline$\left(\begin{array}{lll}1 & a & 2\end{array}\right)$ & 16 & 3,08 & 0,52 & 10 & 3,10 & 0,61 \\
\hline$\left(\begin{array}{lll}2 & a & 3\end{array}\right)$ & 12 & 3,22 & 0,41 & 7 & 3,26 & 0,56 \\
\hline$\left(\begin{array}{lll}3 & a & 5\end{array}\right)$ & 15 & 3,35 & 0,54 & 10 & 3,72 & 0,56 \\
\hline$\left(\begin{array}{l}5 \text { a } \\
6\end{array}\right.$ & 45 & 3,19 & 0,52 & 32 & 3,19 & 0,50 \\
\hline$\left(\begin{array}{c}10 \text { a } \\
7\end{array}\right.$ & 99 & 3,31 & 0,54 & 54 & 3,33 & 0,59 \\
\hline$(+$ de 20$)$ & 115 & 63,0 & 0,66 & 66 & 3,25 & 0,43 \\
\hline
\end{tabular}

5.10.b)

TABELA 30

Significância das médias entre os agrupamentos combinados

\begin{tabular}{c|c|c|c|c|c}
\hline Combinados & $\begin{array}{c}t-1 \\
\text { Avaliação }\end{array}$ & $\begin{array}{c}t-2 \\
\text { Entrevista }\end{array}$ & Combinados & $\begin{array}{c}t-1 \\
\text { Avaliação }\end{array}$ & $\begin{array}{c}t-2 \\
\text { Entrevista }\end{array}$ \\
\cline { 2 - 3 } $1 \times 2$ & 1,00 & 0,20 & $3 \times 4$ & 0,72 & 1,70 \\
$1 \times 3$ & 1,93 & 0,70 & $3 \times 5$ & 0,21 & 0,31 \\
$1 \times 4$ & 2,44 & 2,42 & $3 \times 6$ & 0,69 & 0,31 \\
$1 \times 5$ & 2,00 & 0,62 & $3 \times 7$ & 1,23 & 0,04 \\
$1 \times 6$ & 3,07 & 1,20 & $4 \times 5$ & 1,06 & 2,78 \\
$1 \times 7$ & 1,15 & 0,91 & $4 \times 6$ & 0,28 & 2,05 \\
$2 \times 3$ & 0,82 & 0,57 & $4 \times 7$ & 1,93 & 2,61 \\
$2 \times 4$ & 1,42 & 2,38 & $5 \times 6$ & 1,33 & 1,27 \\
$2 \times 5$ & 0,73 & 0,42 & $5 \times 7$ & 1,44 & 0,60 \\
$2 \times 6$ & 1,64 & 1,15 & $6 \times 7$ & 3,12 & 0,88 \\
$2 \times 7$ & 0,14 & 0,75 & & & \\
\hline
\end{tabular}

TABELA 28

Significância das médias entre os agrupamentos combinados

\begin{tabular}{c|c|c|c|c|c}
\hline Combinados & $\begin{array}{c}t-1 \\
\text { Avaliação }\end{array}$ & $\begin{array}{c}t-2 \\
\text { Entrevista }\end{array}$ & Combinados & $\begin{array}{c}t-1 \\
\text { Avaliação }\end{array}$ & $\begin{array}{c}t-2 \\
\text { Entrevista }\end{array}$ \\
\cline { 2 - 3 } $1 \times 2$ & 1,72 & 0,77 & $3 \times 4$ & 0,50 & 0,41 \\
$1 \times 3$ & 2,41 & 0,17 & $3 \times 5$ & 1,00 & 0,20 \\
$1 \times 4$ & 2,83 & 0,44 & $3 \times 6$ & 2,25 & 0,46 \\
$1 \times 5$ & 1,50 & 0,29 & $3 \times 7$ & 3,75 & 1,06 \\
$1 \times 6$ & 0,14 & 0,47 & $4 \times 5$ & 1,60 & 0,27 \\
$1 \times 7$ & 1,14 & 0,90 & $4 \times 6$ & 2,66 & 0,07 \\
$2 \times 3$ & 1,11 & 0,91 & $4 \times 7$ & 4,16 & 0,68 \\
$2 \times 4$ & 1,66 & 0,46 & $5 \times 6$ & 1,23 & 0,30 \\
$2 \times 5$ & 0,10 & 0,75 & $5 \times 7$ & 2,61 & 0,93 \\
$2 \times 6$ & 1,54 & 0,33 & $6 \times 7$ & 1,28 & 0,58 \\
$2 \times 7$ & 2,91 & 0,29 & 6 & & \\
\hline
\end{tabular}

Pela tabela 30-t-2, o agrupamento. 4 é significativamente melhor do que todos os uutros, exceto melhor do que o 3 .

Sendo assim os melhores, avaliados no desempenho funcional, são aquêles com algum tempo de companhia.

Muito tempo de companhia vem associads a mais idade, fator êste que pode interferir no. desempenho funcional. 
TABELA 31

\begin{tabular}{|c|c|c|c|c|c|c|}
\hline \multicolumn{7}{|c|}{ Resultados dos agrupamentos de acôrdo com o tempo de supervisão } \\
\hline \multirow{2}{*}{ Tempo de supervisão } & \multicolumn{3}{|c|}{ Avaliação de desempenho } & \multicolumn{3}{|c|}{ Entrevista } \\
\hline & $\mathbf{N}$ & $\mathbf{M}$ & $\mathbf{s}$ & $\mathbf{N}$ & $\mathbf{M}$ & $\mathbf{s}$ \\
\hline$\left(-\mathrm{de}^{1} 1\right.$ ano) & 34 & 2,92 & 0,42 & 17 & 2,96 & 0,48 \\
\hline$\left(\begin{array}{lll}1 & a & 2\end{array}\right)$ & 75 & 3,23 & 0,58 & 46 & 3,31 & 0,45 \\
\hline$\left(\begin{array}{cc}3 a & 5\end{array}\right)$ & 46 & 3,35 & 0,56 & 28 & 3,44 & 0,61 \\
\hline$\left(\begin{array}{c}6 \text { a } \\
5\end{array}\right.$ & 72 & 3,22 & 0,47 & 47 & 3,18 & 0,47 \\
\hline$\left(\begin{array}{lll}11 & a & 20 \\
6\end{array}\right)$ & 67 & 3,17 & 0,68 & 40 & 3,32 & 0,57 \\
\hline$(+\mathrm{de} 20)$ & 21 & 2,81 & 0,65 & 8 & 3,39 & 0,44 \\
\hline
\end{tabular}

5.11.b)

TABELA 32

\begin{tabular}{|c|c|c|c|c|c|}
\hline \multicolumn{6}{|c|}{ Significáncia das médias entre os agrupamentos combinados } \\
\hline Combinados & $\begin{array}{c}t-1 \\
\text { Avaliação }\end{array}$ & $\begin{array}{c}t-2 \\
\text { Entrevista }\end{array}$ & Combinados & $\begin{array}{c}t-1 \\
\text { Avaliação }\end{array}$ & $\begin{array}{c}t-2 \\
\text { Entrevista }\end{array}$ \\
\hline $\begin{array}{l}1 \times 2 \\
1 \times 3 \\
1 \times 4 \\
1 \times 5 \\
1 \times 6 \\
2 \times 3 \\
2 \times 4 \\
2 \times 5\end{array}$ & $\begin{array}{l}3,44 \\
4,30 \\
3,33 \\
2,50 \\
0,73 \\
1,20 \\
0,12 \\
0,60\end{array}$ & $\begin{array}{l}2,69 \\
3,00 \\
1,69 \\
2,57 \\
2,26 \\
1,00 \\
1,44 \\
0,09\end{array}$ & $\begin{array}{l}2 \times 6 \\
3 \times 4 \\
3 \times 5 \\
3 \times 6 \\
4 \times 5 \\
4 \times 6 \\
5 \times 6\end{array}$ & $\begin{array}{l}2,80 \\
1,44 \\
1,63 \\
3,37 \\
0,55 \\
2,73 \\
2,25\end{array}$ & $\begin{array}{l}0,50 \\
2,00 \\
0,85 \\
0,26 \\
1,27 \\
1,23 \\
0,41\end{array}$ \\
\hline
\end{tabular}

5.12.a)

TABELA 33

Resultados da avaliaça de desempenho nos agrupamentos com caracteristicas especificas (ver 3.4)

\begin{tabular}{c|c|c|c}
\hline Agrupamentos & N & M & S \\
\hline 1 & 33 & 2,75 & 0,98 \\
2 & 15 & 2,79 & 0,62 \\
3 & 6 & 3,07 & 0,35 \\
4 & 11 & 2,99 & 0,33 \\
5 & 18 & 3,25 & 0,35 \\
6 & 20 & 3,19 & 0,47 \\
7 & 37 & 3,18 & 0,50 \\
8 & 28 & 3,19 & 0,51 \\
\hline
\end{tabular}

5.12.b)

TABELA 34

\begin{tabular}{c|c|c|c|c|c}
\hline \multicolumn{6}{c}{ Significancia das médias entre os agrupamentos combinados } \\
\hline Combinados & $T$ & Combinados & $T$ & Combinados & $T$ \\
\hline $1 \times 2$ & 0,17 & $2 \times 6$ & 2,10 & $4 \times 6$ & 1,42 \\
$1 \times 3$ & 1,45 & $2 \times 7$ & 2,29 & $4 \times 7$ & 1,58 \\
$1 \times 4$ & 1,26 & $2 \times 8$ & 2,22 & $4 \times 8$ & 1,53 \\
$1 \times 5$ & 2,77 & $3 \times 4$ & 0,47 & $5 \times 6$ & 0,46 \\
$1 \times 6$ & 2,20 & $3 \times 5$ & 1,12 & $5 \times 7$ & 0,63 \\
$1 \times 7$ & 2,38 & $3 \times 6$ & 0,70 & $5 \times 8$ & 0,50 \\
$1 \times 8$ & 2,31 & $3 \times 7$ & 0,68 & $6 \times 7$ & 0,07 \\
$2 \times 3$ & 1,33 & $3 \times 8$ & 0,70 & $6 \times 8$ & 0,00 \\
$2 \times 4$ & 1,11 & $4 \times 5$ & 2,16 & $7 \times 8$ & 0,08 \\
$2 \times 5$ & 2,55 & & & & \\
\hline
\end{tabular}


Observando a tabela 31 , temos o agrupamento 3 melhor nos dois resultados. Os agrupamentos 1 e 6 apresentam-se inferiores a todos os outros, respectivamente na avaliação de desempenho funcional e na entrevista.

Pela tabela 32-t-1, o agrupamento 3 é melhor do que os agrupamentos extremos: $1 \mathrm{e}$ 6. 0 agrupamento 6 é inferior a todos os outros no seu desempenho funcional; mas se equivale ao 1 .

Pela tabela $32-t-2$, vemos que a inferioridade do agrupamento 1 é significativa quando

\subsection{3}

TABELA 35

Médias dos testes fatoriais em cada cargo em têrmos de percentis da população

\begin{tabular}{c|c|c|c|c|c}
\hline \multirow{2}{*}{ Fatôres } & \multicolumn{5}{|c}{ Cargos } \\
\cline { 2 - 6 } & CCM & CM & AT & AA & DS \\
\hline G & 55 & 40 & 75 & 55 & 70 \\
N & 60 & 40 & 70 & 65 & 70 \\
S & 50 & 50 & 65 & 50 & 65 \\
R & 65 & 45 & 75 & 65 & 55 \\
V & 55 & 40 & 75 & 65 & 65 \\
W & 55 & 40 & 70 & 60 & 70 \\
P & 60 & 45 & 65 & 55 & 50 \\
\hline Avaliação & 3,67 & 3,03 & 3,19 & 3,28 & 3,43 \\
Entrevista & 3,71 & 3,22 & 3,09 & 3,22 & 3,27 \\
\hline
\end{tabular}

Expomos aqui uma tabela-resumo dos resultados dos supervisores. Nos fatôres, as médias encontradas foram transformadas em percentis pela escala da população.

Nos resultados da avaliação e da entrevista as médias estão apresentadas em seus valóres absolutos.

Os chefes-contramestres têm percentis medianos e os melhores resultados no desempenho funcional e na entrevista.

Os contramestres formam o grupo pràticamente mais fraco, mas, no fator $\mathbf{S}$, é quase equivalente aos outros.

Os auxiliares técnicos têm os melhores percentis, a menor comparada aos agrupamentos 2 , 3 e 6.

A tabela 33 vem confirmar nossas observações anteriores: a maior média de desempenho foi conseguida pelo agrupamento 5 . Este engloba os indivíduos jovens com cinco anos, no mínimo, de experiência na companhia. Este agrupamento apresenta-se significativamente melhor (tabela 34) do que os idosos e melhor do que os jovens de idade equivalentes, porém, sem experiência na companhia. Os grupos 1 e 2 que são os mais idosos, são inferiores a todos os outros.

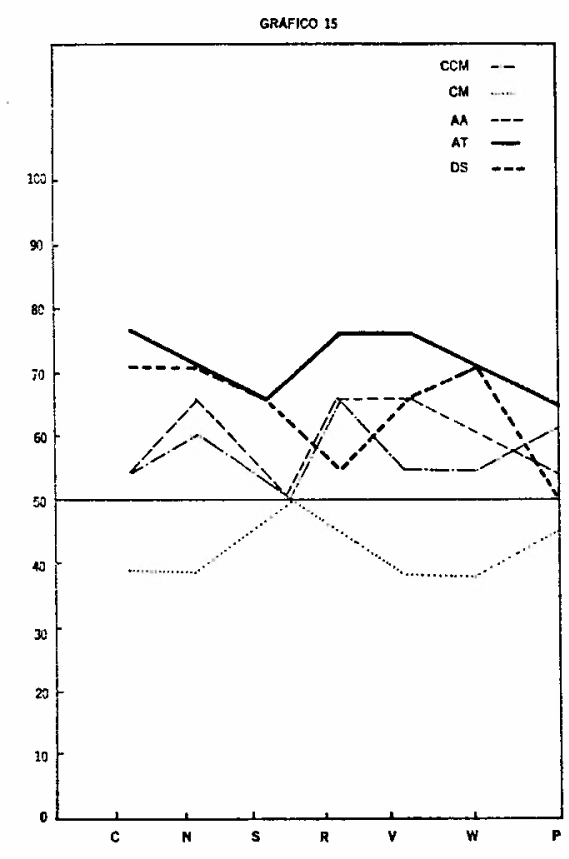

5.14. Traços de maior e menor importância para a supervisão

Traços mais valorizados pela população para o bom desempenho na função foram: conhecimento de trabalho supervisionado, honestidade geral, aptidão para chefiar e fidelidade à companhia; e os menos valorizados foram: pêso e altura.

\section{DISCUSSAO DE ALGUNS CASOS PARTICULARES}

Com o intuito de enriquecermos alguns aspectos de nossa pesquisa, resolvemos tomar entre a população dos supervisores alguns casos particulares para um estudo mais pormenorizado.

Para a escolha dêstes casos adotamos o seguinte critério: selecionamos todos os supervisores que obtiveram uma nota de avaliação de desempenho superior a 4,0 e, dentre êles, sorteamos quatro; e, dentre os supervisores que tiveram a nota de avaliação inferior a 2,5, também sorteamos quatro.

Para chegarmos a conclusões posteriores fornecemos alguns dados pessoais de cada um, 
assim como seus resultados na bateria fatorial, na avaliação de desempenho na função e na entrevista, sendo que desta última apresentamos também uma síntese dos sentimentos e informações prestadas pelo entrevistado.

Observamos pelos gráficos que os supervisores teriam percentis mais altos se fôssem avaliados pelas escalas da bateria CEPA. Podemos admitir que a nossa população deu resultados mais altos do que a amostra da bateria CEPA, composta de estudantes adolescentes.

Dados pessoais:

Dados pessoais:

Idade:

De 21 a 25 anos Idade:

De 31 a 35 anos

Escolaridade:

Técnico

Escolaridade:

Técnico

Tempo de companhia:

De 1 a 2 anos Tempo de companhia:

De 5 a 10 anos

Tempo de supervisão:

Menos de 1 ano Tempo de supervisão:

De 6 a 10 anos

\section{Síntese da entrevista:}

Gostou muito de fazer os testes e está interessado em seus resultados, como também em complementar os exames para receber uma orientação vocacional.

Ao entrar para a companhia, sentiu-se desambientado primeiro pela falta de experiência profissional e segundo por não ter sido bem recebido pelos colegas. Tem observado que, de fato, não há camaradagem e colaboração entre os supervisores.

Apesar de ter formação técnica, até hoje não utilizou seus conhecimentos no serviço, por ser êste essencialmente simples e rotineiro, o que the traz insatisfação.

Considera como qualidades importantes do supervisor o conhecimento do seu trabalho, ter um certo grau de instrução e saber tratar as pessoas.

Sente-se insatisfeito na área onde trabalha, pela falta de organização administrativa, pelo horário noturno, pelo ambiente que considera perigoso, sujeito a sofrer um acidente a qualquer momento e, finalmente, pelo salário que não é compensador.

Apreciação: Revela grande insatisfacão, principalmente, na área profissional.

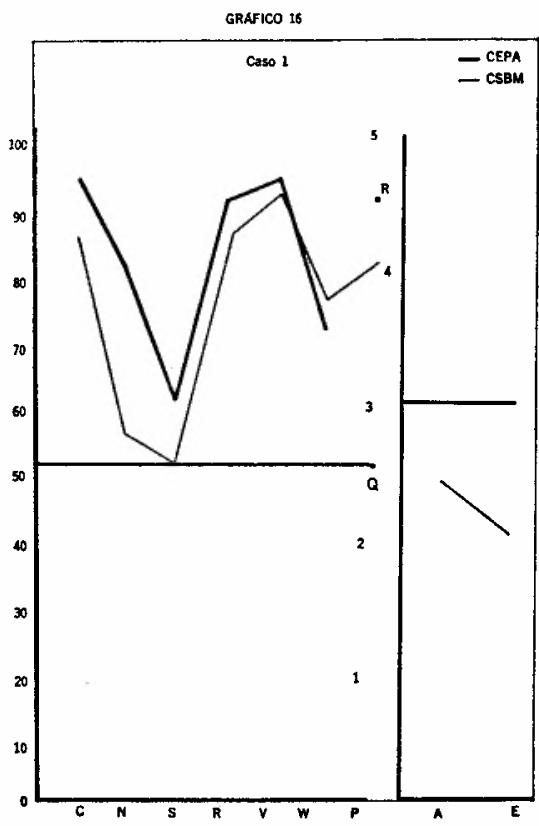

\section{Síntese da entrevista:}

Mostrou-se bastante interessado em conhecer seus resultados nos testes.

Sente que ainda não há na emprêsa uma definição clara quanto ao cargo que ocupa, desconhecendo, portanto, a sua posição e seu valor na área em que trabalha.

\section{Considera como qualidades}

importantes para o supervisor o conhecimento do trabalho supervisionado e da área de um modo geral, como também o

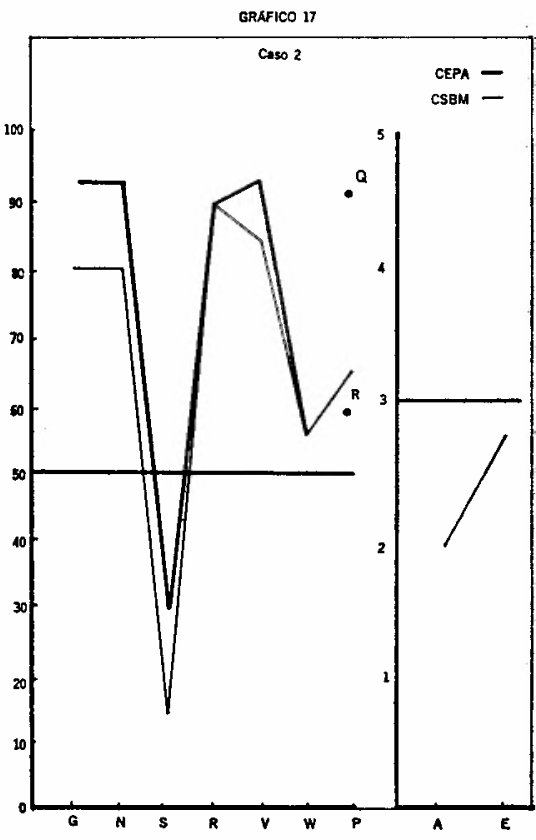

o bom relacionamento com as pessoas.

A pouca motivação para o trabalho, decorrente da falta de incentivos assim como a deficiência nas comunicações descendentes trazem-Ihe insatisfações.

Apreciação: Pessoa preocupada com o seu sucesso profissional como também com sua adaptação na função. Revela insatisfação e pouco entusiasmo no trabalho, principalmente por não se sentir valorizado. 


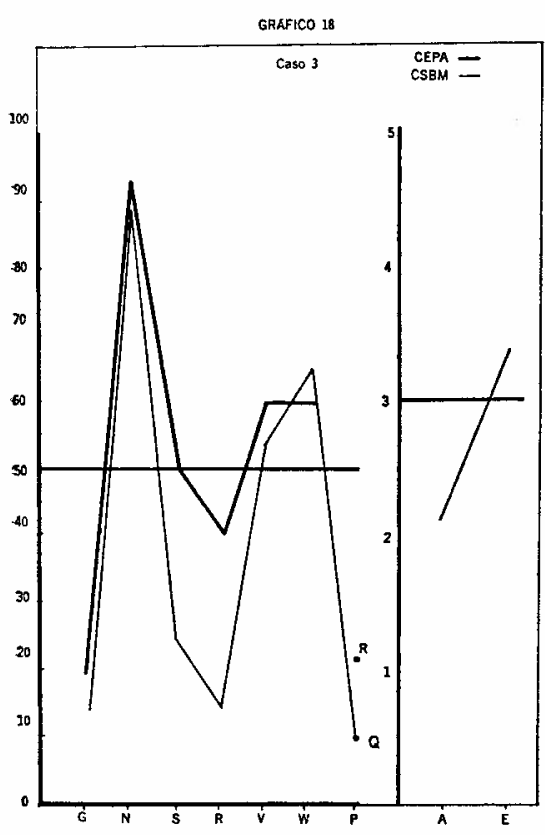

Dados pessoais:

idade:

De 21 a 25 anos

Escolaridade:

Primário completo

Tempo de companhia:

De 5 a 10 anos

Tempo de supervisão:

De 1 a 2 anos

\section{Síntese da entrevista:}

Achou os testes muito interessantes.

Foi admitido na companhia como contínuo, passando, após alguns anos, a ocupar cargo de supervisão.

Gosta muito de seu trabalho, apesar de achar que não possui as qualidades necessárias para bem desempenhá-lo, a saber: grau de instrução, pelo menos, equivalente ao curso ginasial e ser calmo e tranqüilo.

Considera como causa de insatisfação o salário que é pouco pelo trabalho que faz.

Apreciação: $O$ supervisor sente que exerce uma função acima de suas capacidades e não ganha pelo que faz, o que the traz insatisfação. Segundo Elliot Jacques, a capacidade, o trabalho e a remuneração devem estar no mesmo nível para que o indivíduo sinta-se satisfeito.

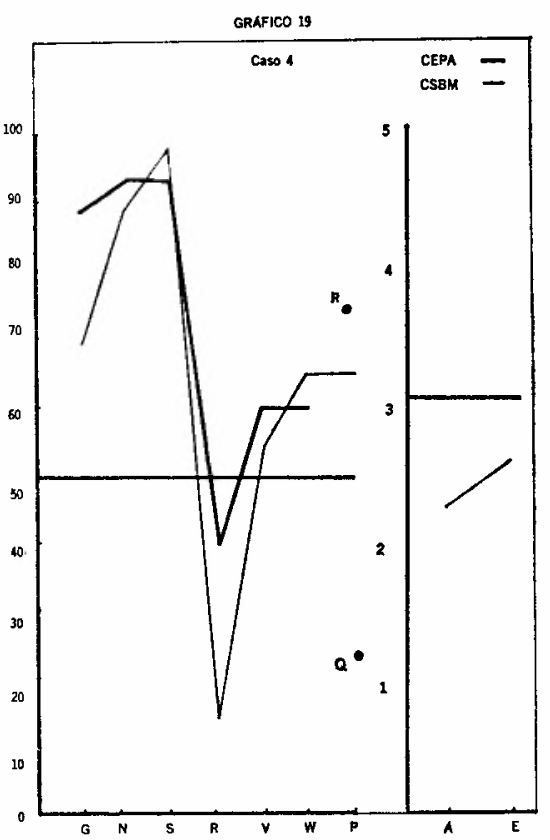

Dados pessoais:

Idade:

De 31 a 35 anos

Escolaridade:

Primário completo

Tempo de companhia:

De 10 a 20 anos

Tempo de supervisão:

De 3 a 5 anos

Síntese da entrevista:

Sentiu-se muito interessado pela realização dos testes, principalmente, por ser novidade para êle.

Desde que entrou para a companhia exerce a mesma função. Gosta do seu serviço, apesar de considerar desagradável 0 ambiente em que trabalha, principalmente no que diz respeito ao relacionamento entre as pessoas, acarretando dificuldades no exercício de sua função.

Apresenta como qualidades importantes para o supervisor: ser comunicativo, respeitar e se interessar por seus subordinados auxiliando-os na resolução de seus problemas.
Apreciação: Pessoa insatisfeita no trabalho, principalmente com relação à chefia.

Segundo Daniel Katz, é fator de insatisfação para os subordinados possuir um chefe inadequado em sua função.

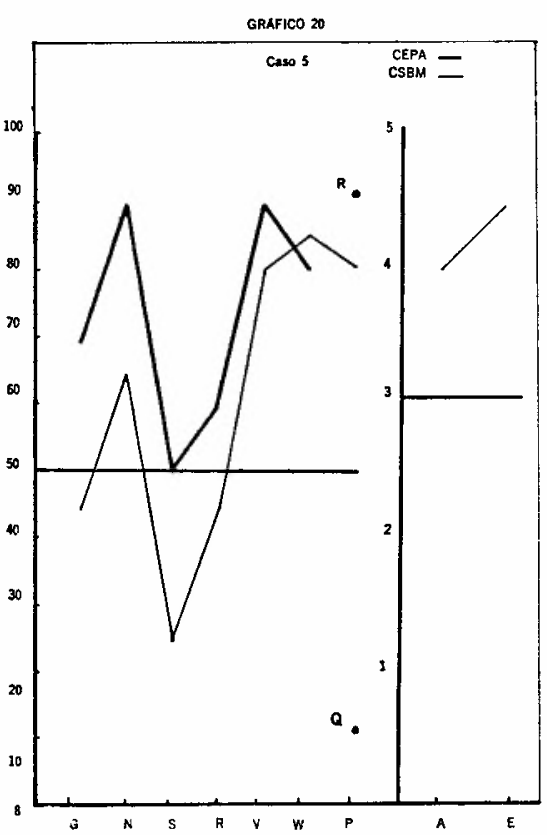

Dados pessoais:

Idade:

De 26 a 30 anos

Escolaridade:

Técnico

Tempo de companhia:

De 5 a 10 anos

Tempo de supervisão:

De 3 a 5 anos

\section{Síntese da entrevista:}

Sentiu-se muito satisfeito em realizar os testes e em participar da pesquisa.

Iniciou-se na companhia como ajudante braçal e sempre teve as melhores oportunidades para progredir na emprêsa. Após realizar o curso técnico de nível médio, passou a ocupar cargo de supervisão.

Mostra-se bastante entusiasmado com o trabalho que faz, por Ihe trazer vários 
benefícios, principalmente, 0 aprimoramento técnico.

Apresenta como qualidade mais importante, para o supervisor no desempenho de suas funções, desenvolver um bom relacionamento com o pessoal num clima de confiança e liberdade no trabalho.

\section{Apreciação: Pessoa adaptada} em sua função, manifestando grande entusiasmo pelo trabalho que faz.

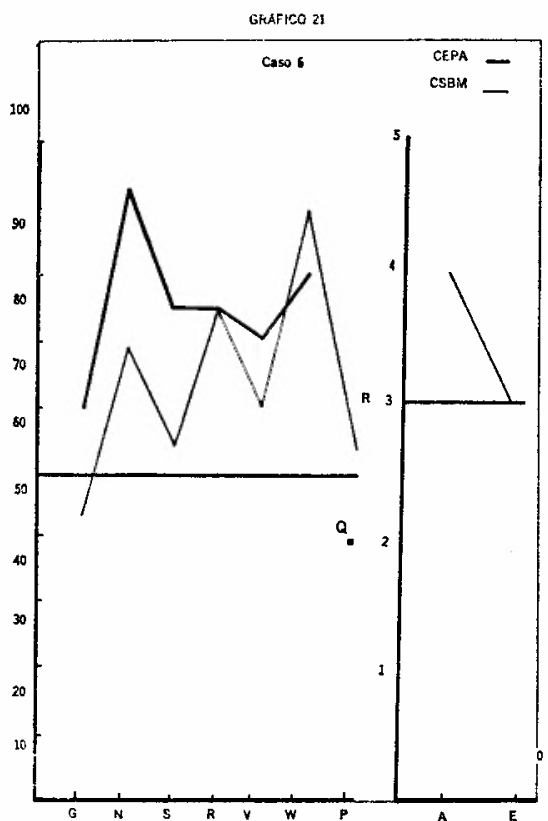

Dados pessoais:

Idade:

De 31 a 35 anos

Escolaridade:

Primário completo

Tempo de companhia:

De 10 a 20 anos

Tempo de supervisão:

De 1 a 2 anos

\section{Síntese da entrevista:}

Gostou muito dos testes, mas acredita que não tenha se saído bem.

Sempre trabalhou na companhia em funções de escritório porque o consideram eficiente nesta área, mas pessoalmente isto nunca lhe agradou, por achar baixo o seu salário, por não ter chance de progreso e não ser valorizado no exercício de sua função.

Considera a in iciativa o fator mais importante para desempenhar bem as funções de supervisor.

O maior problema que encontra em seu trabalho é não ter subordinados à altura do cargo que ocupam.

\section{Apreciação: Pessoa} capaz, mas insatisfeita profissionalmente.

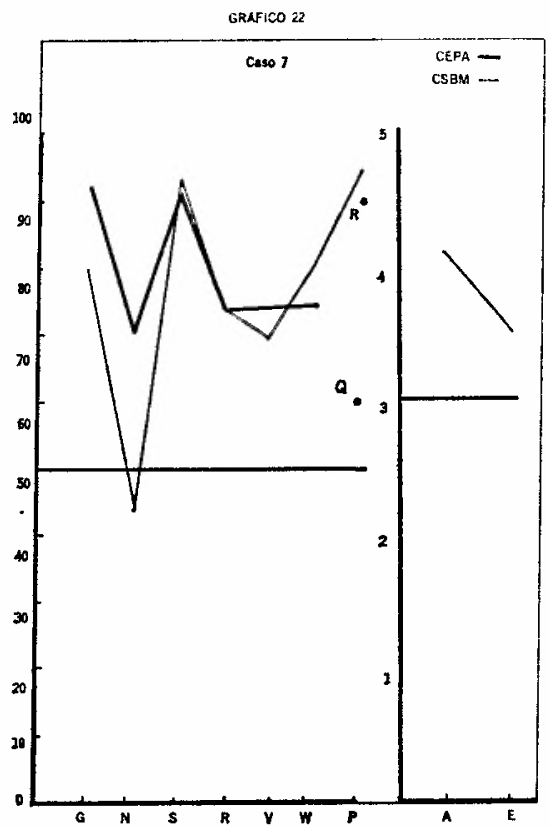

Dados pessoais:

Idade:

De 21 a 25 anos

Escolaridade:

Técnico

Tempo de companhia:

De 3 a 5 anos

Tempo de supervisão:

De 3 a 5 anos

Síntese da entrevista:

Gostou muito dos testes e, apesar de ter trabalhado na noite que precedeu a realização dos mesmos, acredita que isto não Ihe tenha prejudicado.

Entrou para a companhia como estagiário e logo que foi admitido passou a exercer supervisão.

Aponta como qualidades importantes do supervisor: o conhecimento da área supervisionada, ser ponderado em suas decisões e saber tratar o pessoal.

Observa que no treinamento dos subordinados o que lhe traz dificuldades é a baixa escolaridade dos mesmos.

Gosta muito de seu trabalho, mas considera o horário noturno e a poeira intensa, fatôres de insatisfação.

Apreciação: Pessoa profissionalmente adaptada em suas funções.

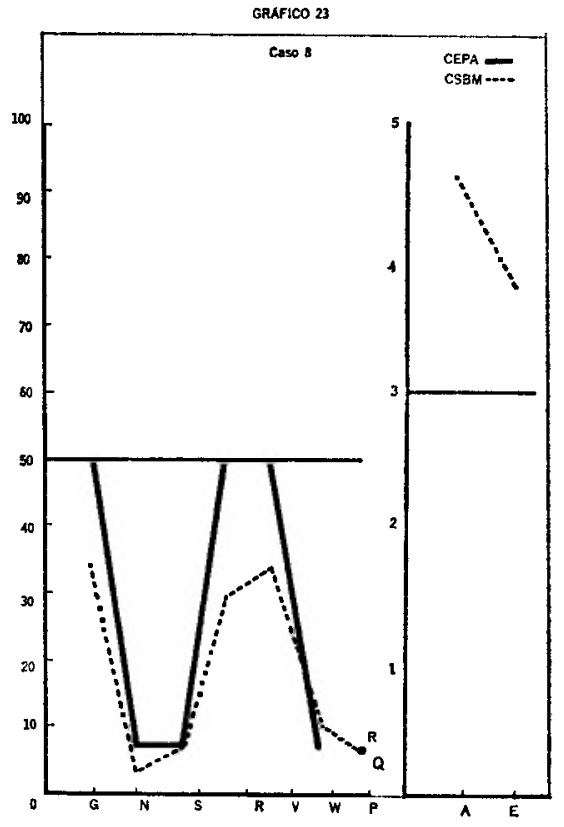

Dados pessoais:

Idade:

De 41 a 45 anos

Escolaridade:

Primário completo

Tempo de companhia:

Mais de 20 anos

Tempo de supervisão:

De 11 a 20 anos 


\section{Síntese da entrevista:}

Sentiu-se muito nervoso para fazer os testes - o que sempre lhe acontece em situações semelhantes - além de considerá-los muito difíceis.

Iniciou-se na companhia como ajudante e, profissionalmente, teve um desenvolvimento rápido pela facilidade que sentia em aprender o serviço, chegando a ocupar em pouco tempo cargos de chefia.

Considera como fatôres importantes para exercer a supervisão um bom conhecimento da área de trabalho e um bom relacionamento com o pessoal, evitando-se o favoritismo.

Mostra-se interessado em acompanhar de perto o trabalho em realização na sua área, preocupando-se com 0 desenvolvimento e a formação técnica de seus subordinados. Procura discutir com os mesmos todos os planos a serem executados.

Apreciação: Pessoa adaptada e satisfeita profissionalmente. Demonstra bem, senso de organização e administração de pessoal.

\section{CONCLUSŌES}

1. Os supervisores com formação técnica revelam um potencial em aptidões tanto gerais como específicas muito superior aos supervisores não técnicos.

\section{Embora com potencial} superior, os supervisores com formação técnica não se mostraram superiores aos não técnicos no desempenho funcional.

A formação técnica sòzinha não é fator de melhor desempenho.
Outras medidas devem ser tomadas no sentido de que o supervisor técnico dê maior rendimento em decorrência de suas capacidades.

3. Sob o ponto de vista do ajustamento na função, o supervisor técnico não tem muita chance de ser superior ao não técnico.

Além de cursos especializados são necessárias condições que que garantam ao supervisor melhor adaptação e satisfação no trabalho.

4. Os supervisores técnicos trabalham mais na dependência de aptidões específicas e os não técnicos na dependência de um fator geral. Logo a formação técnica contribui, de alguma forma, para o rendimento do supervisor.

5. Os chefes-contramestres alcançaram resultados significativamente melhores do que todos os outros nas duas avaliações: desempenho funcional e entrevista. Nos fatôres apresentaram rendimento apenas médio. 0 melhor ajustamento que demonstraram, mais do que o rendimento apresentado, seria o fator de seu sucesso profissional. A satisfação de ter atingido êste cargo e os benefícios dêle decorrentes constituiriam motivações para o bom desempenho na função.

Segundo Claudine Marenco, a perspectiva de progresso numa emprêsa como também o valor social do salário são fatôres primordiais para a satisfação do indivíduo.

6. Os auxiliares técnicos tiveram melhor rendimento em tôdas as provas da bateria fatorial, demonstrando melhor potencial intelectual. No entanto, obtiveram avaliação de desempenho na função quase no mesmo nivel de todos os outros. Poderiam os auxiliares técnicos ser mais solicitados, a fim de que, na medida de suas potencialidades, pudessem produzir mais.

Os contramestres conseguiram os menores resultados tanto na bateria fatorial como na avaliação de desempenho na função. Êstes fatôres estariam aqui ligados de alguma forma.

7. Os supervisores muito novos obtiveram as menores avaliações tanto no desempenho como na entrevista. Os

supervisores na falxa de 30 a 40 anos chegaram às melhores avaliações de desempenho e a graus médios na entrevista.

Os supervisores idosos apresentaram as menores avaliações de desempenho funcional, mas os maiores graus na entrevista.

Algum tempo de companhia e supervisão são importantes ao bom ajustamento do supervisor, em decorrência de que o seu desempenho na função é mais valorizado.

O supervisor aos 50 anos tem probabilidade de estar mais ajustado, mas, em decorrência da idade, tem probabilidade de apresentar um desempenho funcional menos valorizado.

De acôrdo com os objetivos propostos podemos sintetizar, assim, nossas conclusões:

Um diagnóstico de aptidões específicas, de acôrdo com as funções que irão desempenhar, é indispensável num trabalho de seleção de supervisores.

E também indispensável um diagnóstico de ajustamento socioprofissional. 
Selecionar os supervisores ao entrarem na emprêsa não é suficiente ao desempenho ideal na função. Formação técnica sòzinha não garante maior produção. É necessário que o supervisor encontre ambiente favorável ao seu ajustamento e condições de trabalho razoáveis.

Supervisores com maior capacidade devem ser encaminhados a trabalhos em que sejam melhor aproveitados para que trabalho e capacidade estejam no mesmo plano horizontal.

Algum tempo de prática ou de companhia é necessário ao supervisor para seu ajustamento e seu melhor desempenho na função.

Perspectivas positivas na emprêsa são fatôres de melhor desempenho na função.

Atendendo, ainda, aos nossos objetivos, levantamos as escalas de avaliação nos testes fatoriais que estarão à disposição do serviço de seleção da emprêsa.

\section{REFERENCIAS BIBLIOGRAFICAS}

Aleixandre, J. J. Herrero. Teoria de la valoración de personal. Madrid, Ediciones Rialp.

Bavelas, Alex. Padrões de comunicação em grupos orientados para a tarefa. Dinâmica de grupo. De Cartwright \& Zander. São Paulo, Herder Editôra, 1967.

Blalack Jr., Hubert M. Estadística social. México, Editôra Fondo de Cultura Económica, 1966.
Campos, Francisco. Inteligência ou interêsse? Um teste de vocabulário. Arquivos Brasileiros de Psicotécnica, n. 4, 1967.

Cartwright \& Zander. Dinâmica de grupo. São Paulo, Herder Editôra, 1967.

Cunha, Suzana Ezequiel da. Estatística descritiva. Rio de Janeiro, Forense, 1969.

Edwards, Allen L. Experimental. design in psychological research. New York, Rinehart \& Company, 1950.

Gardner, B. B. \& Moore, D. G. Relaciones humanas en la empresa. Madrid, Ediciones Rialp, 1961.

Garret, Henry. Estatística na psicologia e na educação. Rio de Janeiro, Editôra Fundo de Cultura, 1968.

Gilmer, B. Von Haller. Psicologia industrial. México, Ediciones Grijalbo, S. A., 1963.

Guilford, J. P. Fundamental statistics in psychology and education. McGraw-Hill Book Company, 1965.

Jacques, Elliot. Avaliação das responsabilidades.

Jucius, Michael J. Introdução à administração.

Katz, Daniel, Maccoby, Nathan \& Morse, Nancy C. Productivity supervision and morale in an office situation. Survey Research Center, University of Michigan, Michigan, 1950.

Knowles, W. H. Principios de dirección de personal. Madrid, Ediciones Rialp, 1965.
Maier, Norman R. F. Psicologia industrial. Madrid, Ediciones Rialp, 1964.

Marenco, Claudine. Aspectos psicológicos da noção de salário e posição. Centro de Estudos de Organização de Escritórios, Edição do Sindicato Nacional dos Empregados de Escritório do Distrito de Lisboa, Portugal.

Nahoum, Charles. La entrevista psicologica. Buenos Aires, Editorial Kapelusz, 1961.

Pacaud, Suzanne. La sélection professionelle. Paris, Presses Universitaires de France, 1959.

Rodrigues, José Ennes \& Araujo, Marcos Goursand de. O psicodiagnóstico de Rorschach em seleção de pessoal. Arquivos Brasileiros de Psicotécnica, n. 4, 1968.

Rogers, Carl R. Psicoterapia centrada en el cliente. Buenos Aires, Editorial Paidós, 1966.

Santos, Oswaldo de Barros. Psicologia aplicada à orientação e seleção profissional. São Paulo, Livraria Pioneira Editôra, 1963.

Siguan, Miguel. Problemas Humanos del trabajo industrial. Madrid, Ediciones Rialp, 1960.

Thomason \& Clement. Relações humanas. São Paulo, IBRASA, 1968.

Tiffin, Joseph \& McCormick, Ernest J. Industrial psychology. London, George Allen \& Unwin Ltd. 1964. 
Vernon, Philip E. The

measurement of abilities.

London, University of London

Press, 1962.

Walter, Léon. Psicologia do

trabalho industrial. São Paulo,

Edições Melhoramentos, 1963.

Weil, Pierre, Garcia, Célio;
Dinâmica de grupo $e$ desenvolvimento em relações humanas. Itatiaia, Belo

Horizonte, 1968.

\section{Dictionary of occupational}

tittles. Occupational

Classification and Industry

Index. U. S. Department of
Manual da bateria Cepa.

Centro de Psicologia Aplicada, Rio de Janeiro, 1961.

Pesquisa nacional sôbre o nível mental da população brasileira. Relator: Pierre Weil, Serviço Nacional de Aprendizagem Comercial, Rio de Janeiro, 1960.

\section{SERIE BIBLIOTECA DE ADMNISTRAGGAO PÚbLICA (BAP)}

Iniciada em 1953 com a edição de "ORGANIZAÇAO E METODOS", de Harry Miller, a série vem obtendo êxito na tentativa de enriquecer a bibliografia especializada através da publicação de obras que reflitam a realidade administrativa.

Do esfôrço resultou a elaboração de manuais de indiscutível valia para os que se dedicam ao estudo e às atividades da administração pública, estudantes, administradores, economistas e cientistas sociais em geral, aos quais são oferecidos formulações de problemas administrativos.

A série "BIBLIOTECA DE ADMINISTRAÇAO PÚBLICA" inscreve-se, ainda, dentro do propósito de contribuir para a formulação de uma doutrina brasileira da administração pública.

Organização e Métodos

Harry Miller

BAP $14 .^{\text {a }}$ edição (a sair)

Técnica de Administração Municipal Associação Internacional de Administradores Municipais

BAP 2

A Arte da Administração

Ordway Tead

BAP $32 .^{a}$ edição

Introdução à Administraçăo Públiça Pedro Muñoz Amato

BAP $14 .^{a}$ edição (a sair)

Introdução ao Planejamento Democrático John R. P. Friedman

BAP 5

Princípios de Finanças Públicas

Hugh Dalton

BAP $62 .^{a}$ edição

Problemas de Pessoal da Emprêsa Moderna

Tomás de Vilanova $M$. Lopes

BAP 7 4. ${ }^{2}$ edição

Administração de Pessoal - Princípios e Técnicas

Beatriz M. de Souza Wahrlich

BAP $82 .^{a}$ edição (a sair)

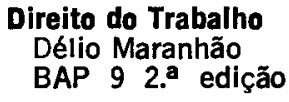

Direito do Trabalho

Délio Maranhão

BAP 9 2.a edição

- Ensino da Administração Pública no Brasil Marina Brandão Machado BAP 10

Classificação das Contas Públicas José T. Machado Jr. BAP 11

Administração e Estratégia do Desenvolvimento A. Guerreiro Ramos BAP 12

A Intervenção do Estado no Domínio Econômico Alberto Venâncio Filho BAP 13

Comunicação em Prosa Moderna Othon M. Garcia BAP 14 2. ${ }^{a}$ edição

Fundações - No Direlto, na Administração Clóvis Zobaran Monteiro e Homero Senna BAP 15

Planejamento Governamental Jorge Gustavo da Costa BAP 16

Custos - Um Enfoque Administrativo G. S. Guerra Leone BAP 17

Nas principais livrarias ou pelo reembôlso postal. Pedidos para a Editôra da Fundaçäo Getélio Vargas, Praia de Botafogo 188, CP 21.120, ZC-05, Rio de Janeiro, GB. 